\title{
Cardiac Chamber Volumetric Assessment Using 3D Ultrasound - a Review
}

\author{
João Pedrosa*a, Daniel Barbosa ${ }^{\mathrm{b}}$, Nuno Almeida ${ }^{\mathrm{a}, \mathrm{c}}$, Olivier Bernard ${ }^{\mathrm{d}}$, Johan Bosch ${ }^{\mathrm{e}}$ and Jan D'hooge ${ }^{\mathrm{a}}$ \\ ${ }^{a}$ Laboratory on Cardiovascular Imaging and Dynamics, KU Leuven, Belgium; ${ }^{b} I C V S / 3 B s$ - PT Government \\ Associate Laboratory, Braga/Guimarães, Portugal; ${ }^{C} G E$ Vingmed Ultrasound AS, Horten, Norway;

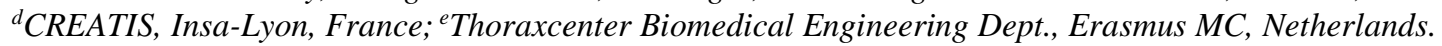

\begin{abstract}
When designing clinical trials for testing novel cardiovascular therapies, it is highly relevant to understand what a given technology can provide in terms of information on the physiologic status of the heart and vessels. Ultrasound imaging has traditionally been the modality of choice to study the cardiovascular system as it has an excellent temporal resolution; it operates in real-time; it is very widespread and - not unimportant - it is cheap. Although this modality is mostly known clinically as a two-dimensional technology, it has recently matured into a true three-dimensional imaging technique. In this review paper, an overview is given of the available ultrasound technology for cardiac chamber quantification in terms of volume and function and evidence is given why these parameters are of value when testing the effect of new cardiovascular therapies.
\end{abstract}

Keywords: Cardiac function; Cardiac volume; 3D echocardiography; Segmentation; Automated analysis; Commercial solutions; Validation studies.

\section{MOTIVATION}

The current global status of cardiovascular diseases, accounting for more deaths than any other cause [1] and projected to remain the leading global cause of death [2], makes the assessment of cardiac volume and function a topic of extreme importance not only in the clinical field for patient diagnostic and follow-up but also in research as new therapies are developed and tested. Several cardiac imaging modalities have arisen to satisfy the demand for cardiac function assessment techniques, among which threedimensional (3D) echocardiography seems to be especially promising. The analysis of the images to obtain the volumetric indices has also been heavily developed in order to extract the information in a fast, exact and userindependent manner.

While much research and clinical attention has been directed towards volumetric assessment of the left ventricle (LV), as detailed in the extensive review of Leung and Bosch, an increased interest in the other cardiac chambers is more recently shifting the focus towards a more comprehensive set of volumetric biomarkers [3]. Thus, this present review presents an accurate description of the current state-of-the-art on cardiac chamber volumetric assessment using three-dimensional ultrasound. The focus is set on the available technologies in clinical practice, as well as the most relevant validation efforts for each cardiac chamber.

This manuscript is organized as follows: Section 2 provides a global perspective on the importance of volumetric cardiac indices and how these can be effectively assessed. The main existing modalities for cardiac imaging are also presented and compared. A brief conceptual description of the available methods for cardiac image

*Address correspondence to this author at the Medical Imaging Research Center, University Hospital Gasthuisberg, Herestraat 49 - bus 7003, B-3000 Leuven, Belgium. E-mail: joao.pedrosa@kuleuven.be processing and automated volumetric assessment is then given in Section 3. Section 4 focuses then on the available software solutions in clinical practice for volumetric biomarkers of cardiac morphology and function for each chamber, while discussing their validation level and relevant clinical findings. Finally, Section 5 concludes the current manuscript with the closing remarks on this topic discussing the present and future challenges for cardiac chamber volumetric assessment.

\section{ASSESSMENT OF CARDIAC MORPHOLOGY AND FUNCTION}

The fundamental cardiac pumping function arises from a sequence of electrical events which trigger the coordinated contraction of the myocardial tissue. These events form the cardiac cycle and are regularly repeated over every heartbeat, being regulated through different pacing mechanisms which control the frequency of cardiac contraction. The rhythmic contraction of the different cardiac chambers results in intrinsic volume variations of both atria and ventricles over the cardiac cycle. From these volume traces, several indices can be extracted to characterize both cardiac morphology and global function such as the end-diastolic and endsystolic volumes (EDV and ESV). In the particular case of the atria these volumes are often referred to as LAmax and LAmin and RAmax and RAmin for the left and right atrium (LA and RA) respectively. It is also common practice to use volume indices divided by body surface area, usually the LA volume index (LAVI) and the RA volume index (RAVI). Furthermore, other cardiac global functional indices can be extracted from volume traces. Stroke volume (SV=EDVESV) is the effective amount of blood ejected by a cavity. The left ventricular SV, when multiplied by the heart rate, gives the total cardiac output (CO). As a measure of pumping efficiency, one can estimate the ejection fraction $(\mathrm{EF}=(\mathrm{SV} / \mathrm{EDV}) \mathrm{x} 100 \%)$, as proposed originally by Pombo et 
al. [4], which is still probably the most widely used parameter to assess the global status of cardiac function in LV [5]. For the atria, this measure is also called emptying fraction. Some specific measures have been proposed for the function assessment in the case of the atria such as the atrial expansion index (LAEI = LASV / LAmin and RAEI = RASV / RAmin). Moreover, atrial volume measured immediately before the atrial contraction (LApreA or RApreA) can be used to derive the passive $($ EFpass $=(E D V$ - preA) / preA) and active $(\mathrm{EFact}=(\mathrm{preA}-\mathrm{ESV}) / \mathrm{ESV})$ components of EF, the former corresponding to the passive emptying resulting from ventricle expansion (atrial conduit function) while the latter corresponds to the active emptying (atrial contractile function) [6].

\subsection{Prognostic value in clinical practice}

Extensive research has been directed at determining the prognostic value of volumetric indices for different illnesses and conditions. A brief review of some of these studies is presented here to illustrate the importance of cardiac volume and function assessment.

\subsubsection{Left Ventricle}

Patient survival after myocardial infarction and its relation to $\mathrm{LV}$ function has been thoroughly described in literature. It was first associated with LV ESV by White et al. [7] and Norris et al. [8]. In a study by Burns et al., it was shown that LV EF had even a superior prognostic value than LV ESV for survival after myocardial infarction [9]. Numerous other studies have given further evidence on the prognostic value of LV EF on both short- and long-term survival after myocardial infarction [10-14]. Furthermore, LV EF has been linked to cardiac arrest events [13], heart failure [15], and arrhythmia suppression and cardiac events [16] in survivors of myocardial infarction. More generally, mortality in patients with coronary artery disease has also been associated with LV EF by Buxton et al. [17].

The prognostic value of LV EF for the mortality in patients with heart failure has also been a subject of much research and discussion with different studies reaching different conclusions as to which population, preserved or reduced LV EF, represents a higher mortality risk $[18,19]$. More recently, two meta-analysis studies, one by Somaratne et al. and a second by a large-scale project (MAGGIC), analyzed data from 17 and 31 studies respectively demonstrating that a higher risk of death is present in patients with heart failure and reduced LV EF [20,21].

$\mathrm{LV}$ function has also been used as a predictor of survival in dilated cardiomyopathy [22,23]. Furthermore, LV EF has been associated to mortality in patients with LV dysfunction [24] and to mortality in end-stage renal disease patients on starting hemodialysis [25]. Some works have also been dedicated to the study of stress and post-stress LV volumes. In Sharir et al. post-exercise LV EF and ESV were associated to cardiac death [26] and in Coletta et al. dobutamine stress testing was used to link stress LV EDV to cardiac events in patients with coronary heart disease [27].

\subsubsection{Left Atrium}

More recently the attention has shifted towards the prognostic value of LA volume and function. LA volume has been associated with diastolic dysfunction by Tsang et al. and also with LV remodeling by Rossi et al. [28,29]. It has also been linked to the onset of cardiovascular diseases [30], future cardiovascular events [31], to the development of congestive heart failure in patients with well-preserved LV function [32] and to the occurrence of ischemic stroke in patients without atrial fibrillation [33]. In a study by Leung et al., LAVI has been associated with the risk of cardiovascular death, heart failure, atrial fibrillation, stroke and myocardial infarction [34] and Ristow et al. have associated it to heart failure hospitalization and mortality [35]. LAVI has also been linked to the survival after myocardial infarction [36,37] and to cardiovascular events in patients with lone atrial fibrillation by Osranek et al. [38]. Finally, LA volume has been shown to have a prognostic value for atrial fibrillation $[39,40]$.

\subsubsection{Right Ventricle}

Some research has also been done into the prognostic value of the right heart, and especially of the right ventricle (RV). Numerous studies relate RV function, and more precisely RV EF, with patient survival in different stages of heart failure [41-45].

The prognostic value of the RV for survival in patients with pulmonary arterial hypertension has also been well explored in the studies by van Wolferen et al. [46] and van der Veerdonk et al. [47]. Furthermore, the post myocardial infarction mortality has been associated to the RV EF measured late after clinical myocardial infarction [48]. RV $\mathrm{EF}$ has also been associated with survival in patients with idiopathic dilated cardiomyopathy [49]. Finally, in a study by Kang et al., the early death of patients with acute pulmonary embolism has been associated to the ratio between the RV and the LV volumes [50].

\subsubsection{Right Atrium}

The prognostic value of RA has been substantially less explored in literature. RAVI was linked to RV systolic dysfunction in patients with chronic systolic heart failure and abnormal RV function by Sallach et al. [51].

\subsection{Available Imaging Modalities}

From the above, it is clear that the assessment of cardiac volumes throughout the cardiac cycle and its associated indices is a fundamental task in diagnostic cardiology routine. Furthermore, these indices can be of paramount importance in the design of studies to show the efficacy of new therapies. To this end, there is a large array of imaging modalities providing insight to cardiac chamber size and function, with some examples shown in Figure 1. 

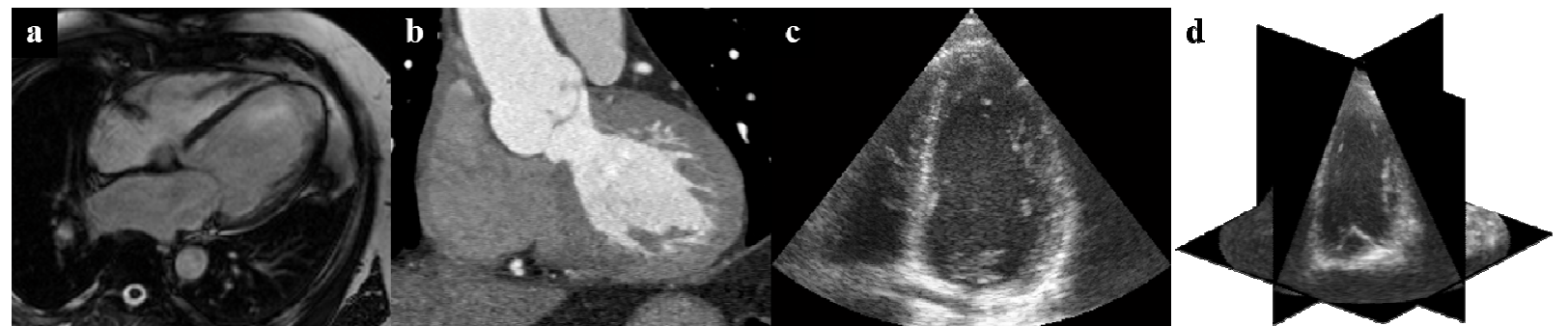

Figure 1. Examples of different cardiac imaging modalities: magnetic resonance imaging (a), computed tomography (b), 2-dimensional echocardiography (c) and 3D echocardiography (d). Computed tomography image courtesy of Walter Coudyzer, Department of

Radiology, UZ Leuven, Belgium.

Magnetic resonance imaging (MRI), and more specifically cardiac MRI (cMRI), is for long considered the gold standard for assessment of cardiac anatomy and analysis of global cardiac function and shape [52]. The key limitations of cMRI are the high cost of the imaging system and the long acquisition times. This last problem is particularly relevant for cardiac imaging, given the fast dynamics of a beating heart. Computed tomography (CT) is one of the fastest evolving imaging modalities. Cardiac CT, which requires the use of contrast agents, offers superb definition of the boundary between the myocardium and the blood pool, excellent spatial resolution $(<1 \mathrm{~mm})$ and good temporal resolution. However, it is a very technically demanding exam, involves exposure to ionizing radiation and is very expensive. Other imaging modalities used include cardiac single photon emission computed tomography (SPECT) and multiple gated imaging strategies (MUGA), also known as radionuclide ventriculography [53,54], positron emission tomography (PET) [55] and other nuclear imaging techniques [56]. However, these techniques require the injection of radioactive contrast agents, thus involving exposure to ionizing radiation, and the imaging systems are typically extremely expensive.

With the exception of standard X-ray exams, ultrasound is the leading imaging modality worldwide [57]. As key imaging advantages, the excellent temporal resolution clearly sets echocardiography apart from the remaining modalities. Other important advantages, such as its safety, good spatial resolution and low cost, also contribute to the widespread use of echocardiography as the cardiac imaging diagnostic exam of reference in daily practice. The use of echocardiography to assess cardiac chamber size and function dates to the advent of this technology. Popp et al. investigated the variation of cardiac dimensions during the cardiac cycle using M-mode echocardiography [58]. Feigenbaum et al. used these changes to assess LV function and correlated it to angiography [59]. Wyatt et al. showed that volumetric indices extracted from two-dimensional (2D) B-mode images were superior to their M-mode counterparts, especially in asymmetrical hearts $[60,61]$. Currently, biplane area assessment using 2D echo is the standard tool for assessment of LV volumetric indices.

\subsection{Real-time 3D echocardiography}

Given the considerations previously mentioned, it becomes clear why current clinical practice in cardiology typically employs 2D echocardiographic studies as the firstline and fundamental exam in the evaluation of cardiac function and morphology of patients, while cMRI is used as a second-line solution for more advanced investigation.

Nonetheless, conventional 2D presents important limitations that directly reduce its potential for accurate volumetric assessment of the different cardiac chambers. Indeed, volume estimation from 2D ultrasound images intrinsically relies on geometric assumptions, which are required to transform the planar measurements into volume estimates. Since the imaging planes may correspond to foreshortened views of the real 3D object, the geometrical assumptions can be easily violated, which in turn leads to reduced accuracy in the volume estimates. Furthermore, during the cardiac cycle, out-of-plane motion can create illusory displacement of the true boundary position, which can further reduce the volumetric assessment accuracy. Thus, the true three-dimensional nature of real-time 3D echocardiography (RT3DE) scanning enables to overcome these limitations, allowing to entirely visualize the morphology of the cardiac chambers. This directly translates into increased agreement of RT3DE against the current goldstandard method (i.e. cMRI) when compared to conventional 2D echocardiography. Summing this to the intrinsic advantages of ultrasound imaging against other modalities, RT3DE will likely become the standard echocardiographic examination of the future.

\section{CARDIAC IMAGE PROCESSING METHODS}

Additionally to the imaging acquisition, the extraction of the relevant information from the data by a software tool must be considered. The assessment of volumetric, functional and morphologic indices poses two main problems. First, a clear identification of the myocardial anatomy is needed, through the delineation of the endo- and epicardial surfaces at a given time point. Furthermore, the position of these boundaries throughout the cardiac cycle is needed to recover the underlying motion of the cardiac chamber and capture the volume changes. Several methods have thus been proposed to address these problems and a categorization of these methods is possible dividing into geometrical models, shape-free methods, statistical models, classification approaches and tracking [3]. Each of these categories is briefly described in this chapter. For a more comprehensive description of these methods, the interested reader can refer to the extensive review by Leung and Bosch [3].

Geometrical models are the most common border detection approaches and consist of the representation of a border in terms of a curved surface influenced by 
geometrical constraints. This surface is initialized interactively or automatically and evolves iteratively according to image features such as the local intensity or edge information. Most geometrical models use energybased optimization where a mathematical energy function is defined according to the image features and other regularization terms and optimized iteratively [62-67]. Given the surface representation that is used, the main disadvantage of these models lies in finding a balance between a surface that is too smooth and one that becomes implausible.

Shape-free methods are, as the name implies, methods with little or no dependency on the shape of the final object. As such, they are heavily dependent on low-level image information such as pixel intensity, gradients, edges and corners and motion vectors. The two main families with this category are clustering and level sets. Clustering is, simply put, a categorization of each pixel of the image into groups, for example myocardial tissue and blood pool [68-71]. Level sets are similar to geometrical models with the main difference that the shape of the object is not restricted, which can often result in multiple disconnected surfaces [72-76]. Due to the low level of shape restrictions imposed, these techniques are quite susceptible to image artifacts such as shadowing or dropouts.

Statistical models are population based methods which model the statistical variations of patient data according to borders manually contoured by experts. This is done by finding a relatively simple mathematical model with but a few parameters that can express the patient variability from an average. By varying these parameters one can then synthetize a large number of shapes. Different sources of information can be used to build such a model. Active shape models use the manual contoured borders [77-79], whereas active appearance models use a combination of the manual contoured borders and the image intensity information [8082]. Given their origin from real examples this method can only find plausible results. However, this is also its downfall as the accuracy of the model will always be dependent on the quality of the original database and its extension throughout both healthy and pathological populations.

Classification approaches are also dependent on large sets of data contoured by experts, with however a different approach than statistical models [83-86]. According to the database information, a classifier is trained to distinguish the objects of interest into classes using appropriate features. In practice, parts of an image are then classified by selecting regions of different sizes in the image in different positions and determining its class following a coarse-to-fine scheme. Though the training procedure is extremely time consuming, the detection can be very fast. Classification approaches suffer from the same disadvantage as statistical models due to its dependency on the original database. However, even larger datasets are typically needed then for statistical models.

Finally, tracking approaches are the most different from the other approaches as they do not aim at the border detection itself but at the estimation of the motion of an object throughout time. Thus, tracking approaches have a more dynamic nature. Since tracking approaches are mostly dependent on image information such as pixel intensity, the results can be especially sensitive to the presence of artifacts. This makes the introduction of information such as cardiac motion patterns particularly interesting. The existing tracking approaches are usually based on either registration or speckle tracking. In registration approaches the spatial correspondence between sequential images is found by measuring and optimizing a measure of similarity between them [64,87-90]. Speckle tracking approaches aim at finding a correspondence between speckle patterns throughout time [91-99].

\section{CARDIAC CHAMBER VOLUME ASSESSMENT USING 3D ULTRASOUND}

\subsection{Left Ventricle}

\subsubsection{Available Technology}

Accurate volume measurements require precise delineation of the LV endocardial border over the entire cardiac cycle. Nonetheless, manual delineation of these boundaries in 3D data is a cumbersome and time-consuming task, making the introduction of this approach in clinical routine impractical. Hereto, several software packages have been introduced to aid the clinician in this contouring process by providing some form of automation.

Tomtec Imaging Systems (Unterschleissheim, Germany) was the first company presenting commercial tools for 3D volume quantification, taking advantage of its expertise on image processing and visualization. Their current product, TomTec 4D LV-Analysis ${ }^{\odot}$, performs an automatic orientation of the LV longitudinal axis to display three apical and three short axis views. If necessary, these can be adjusted by the user to avoid foreshortening and modify the aortic valve landmark orientation. The entire 3D endocardial surface of the left ventricle is then contoured by the software in end-systole and, using 3D speckle tracking, propagated throughout the heart cycle [100]. This same tool is also available under TomTec's software solution 4D LVFunction $^{\mathrm{TM}}$.

Contrarily to the purely offline approach offered by TomTec, Philips Healthcare (Best, Netherlands) introduced the possibility of both offline and online analysis with their QLAB - 3DQ Advance (3DQA) software suit [101,102]. First, the longitudinal axes must be aligned in the 4-chamber and 2-chamber views at the end-diastolic phase. Five anatomical landmarks must then be marked, which are used to initialize a deformable shell model [62]. This model is afterwards deformed towards the LV boundaries, with the option for manual correction. The same process must be completed for the end-systolic phase [102]. Philips Healthcare is currently preparing to introduce a new commercial tool, HeartModel ${ }^{\mathrm{AI}}$, which will be available on their EPIQ7 system and should be released by August 2015. The HeartModel ${ }^{\mathrm{AI}}$ is a fully automatic knowledge-based model which detects end-diastolic and end-systolic instances, performs localization and tracking of the four chambers and also alignment of the apical 4-, 3- and 2chamber views [103]. Refinement of the results is also possible through manual correction of the contours. The tool returns then the LV and LA volumes at end-systole and enddiastole. 
More recently, also General Electric (GE Vingmed, Horten, Norway) introduced a software package, 4D AutoLVQ, which allows both fully or semi-automated segmentation and volume quantification of the left ventricle [100]. In this product, an initial alignment of the axis is needed so as to avoid foreshortening. This can be performed either automatically or manually by pivoting and translating the planes. In the semi-automatic version, the user is required to mark the location of the apex and the mitral annulus at end-diastole and end-systole. After this, the 3D endocardial surface is automatically detected at these instances. In the fully automatic version no initialization points are required. After the conclusion of the segmentation the user is allowed to manually edit the contours.

Toshiba Medical Systems (Tokyo, Japan) has entered the RT3DE realm with its Artida $^{\mathrm{TM}}$ system, which was complemented with a software tool for chamber quantification by 3D echocardiography speckle tracking, 3D Wall Motion Tracking (3D-WMT) [102,104,105]. This computational platform performs an automatic selection of apical 4-chamber and 2-chamber views, as well as 3 shortaxis views at different LV levels. The user is then required to place six markers: at the edge of the mitral valve and at the apex in each of the apical planes. These points are then used to automatically segment the endocardium. The epicardial contour is defined either by a predetermined thickness or through manual contouring. The final shape of the left ventricle can then be corrected manually by the user. A 3dimensional block matching algorithm [106] is then used to track the wall motion throughout the cardiac cycle in a fully automatic manner.

The development of a fully automatic image analysis software package has been one of the main strategic investments of Siemens Medical Solutions (Mountain View, California) while developing their Acuson SC2000 ${ }^{\mathrm{TM}}$ RT3DE system, resulting in the software tool eSie LVA ${ }^{\mathrm{TM}}$ [107]. This tool is based on a comprehensive database of manually annotated RT3DE exams (over 4000) covering both healthy and typical pathological cases in clinical practice. The offline learning process was performed using a Probabilistic Boosting Tree [108] to obtain the final classifier. Given an input volume, this classifier sequentially estimates position, position-orientation and full similarity to locate the object and finally performs both an orientation according to standard planes [86] and also the contouring of the LV using boundary detectors [109] and statistical shape models. The final endocardial contours can be refined by the user through manual correction.

\subsubsection{Validation Efforts}

The enthusiasm generated in the medical community by 2D matrix transducers and RT3DE is well demonstrated by the numerous validation studies for this imaging modality over the past decade. Although validation on other experimental setups has been done (e.g. water balloons of known volume [110], intracavity balloon measurement in canine models [111], in vitro porcine heart models [112]), the primary and more generalized validation route for the existing software suites for volumetric measurement is to perform direct comparison of the volumetric indices extracted from RT3DE exams against reference values extracted from cMRI, which remains the generally accepted gold standard method for volumetric assessment of cardiac chamber dimensions. Alternatively, some studies report a direct comparison between automated vs. manual contouring of RT3DE data, thus providing insight on the ability of automating the contouring process. The most relevant studies are summarized in this sub-section and Table 1 provides an overview of the corresponding main results. Figure 2 shows an example of LV segmentation in 3D echocardiography data.

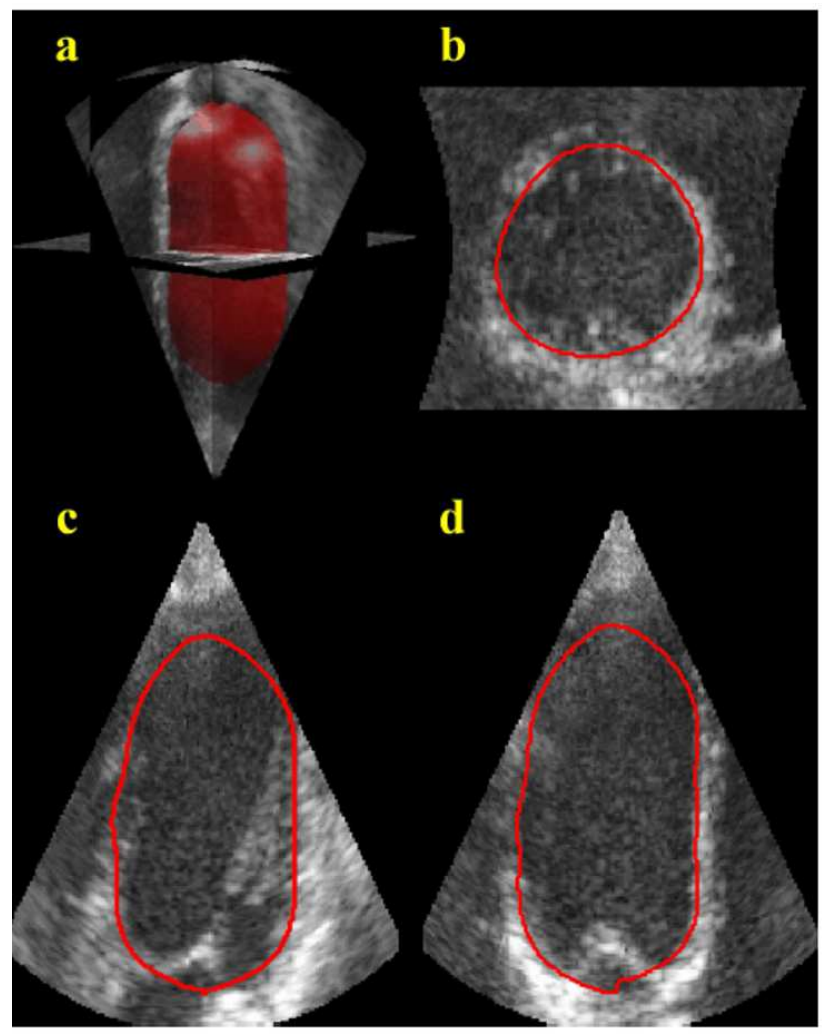

Figure 2. Example of LV segmentation in 3D echocardiography data obtained through a semi-automatic method. a: triplane-view and 3D rendering; $b$ : short-axis view; $c$ and $d$ : long axis views. Reproduced from [67].

The earlier studies focused on software tools which relied mostly on a computer-assisted 3D manual contouring paradigm, either requiring manual delineation of the endocardial boundary in several long axis planes or requiring significant user input in semi-automatic segmentation algorithms. The performance of the pioneer Volumetrics system has been analyzed by both Schimdt et. al [113] and Lee et al. [114]. Both studies found excellent correlation between cMRI-derived volumetric indices and the ones extracted from RT3DE data by manually contouring in different azimuthally equidistant long axis images. Note that Kühl et al. had already demonstrated that the truly 3D nature of RT3DE data enabled long-axis contouring in contrast to the short-axis, sum-of-disk approaches initially inherited from cMRI [115]. Mannaerts et al. performed a similar study with an ATL $^{\circledR}$ HDI 5000 system and manually contouring the endocardium using one of the first TomTec tools, EchoView. Mannaerts et al. reported good correlation as well as the first evidence of a negative bias of 3D echocardiographic volumes with respect to cMRI [116]. Kühl et al. performed 
the first clinical validation on the second generation of 2D (i.e. fully sampled) matrix transducers, showing excellent correlation against cMRI, in a cohort of 24 good image quality patients [117]. In this study, a manual contouring paradigm was compared against an early semi-automatic algorithm, showing that the tested semi-automated approach enabled full 4D delineation but required longer analysis times and showed larger bias and wider limits of agreement. Jenkins et al. have further validated the same system in a larger study $(\#=50)$ using a semi-automatic approach provided in an earlier version of TomTec's 4D LVAnalysis $^{\odot}$ [118]. The tool required the placement of landmarks in 12 azimuthally equidistant long axis views which were used to fit an ellipse to the endocardial borders. This was then followed by manual refinement. In addition to low bias and acceptable limits of agreement, RT3DE showed lower test-retest and intra/inter-observer variability than its 2D counterpart. The same semi-automatic approach was validated by Sugeng et al. with excellent correlation against cMRI and low bias though with wider limits of agreement [119]. Van den Bosch et al. have carried out the first clinical validation of RT3DE-derived LV volumes in congenital heart disease patients, whose challenging cardiac shapes had been previously reported as a difficulty [120]. Their results show excellent correlation/agreement for LV volumetric analysis using a fully manual contouring approach. However, when applying the same semi-automatic contouring software tool as used in [118], the results highlighted that this tool relied too much on a purely elliptical shape prior, thus having a poor performance. Despite the strong resilience of the multi-planar contouring paradigm in the early clinical validation, a more 3D-oriented vision has been introduced with the algorithm proposed by Corsi et al. [73], which was further validated by Caiani et al. in a clinical setting [76].

Jacobs et al. have been the first to validate the concept of rapid, online measurement of LV volumes from RT3DE data [101], using the tool provided by Philips, QLAB 3DQA. Indeed, online volumetric analysis within the imaging system without the need to export data to an external computer for tracing and 3D reconstruction further reduces time load. Very strong correlation and acceptable limits of agreement were found for all volumetric indices, despite the significant bias for EDV and ESV. Additionally, the comparison between the volumetric indices extracted online correlated strongly and had good agreement against the offline semi-automatic contouring approach proposed in [117]. Nonetheless, in a study by Jenkins et al., the offline approach by TomTec was compared to Philips' QLAB 3DQA showing that offline approaches remain superior to the online quantification of LV volumetric indices, at the expense of longer analysis times [121]. A similar study was conducted by Soliman et al. using a newer version of TomTec's 4D LV-Analysis ${ }^{\odot}$ in which only the manual contouring of three orthogonal planes is needed and similar results as those by Jenkins et al were obtained [122]. In a different study by Soliman et al., two different versions of TomTec's 4D LV-Analysis ${ }^{\circledR}$ are compared to volumes obtained through cMRI showing strong correlation for both methods and a clear superiority of the newer version dependent on full volume reconstruction [123].
Despite the convincing results of the previous validation studies, a clearer understanding of possible sources of errors was required for optimal clinical usage. To this end, Mor-Avi et al. have studied the source of variation between volumetric indices measured with RT3DE and cMRI, showing that the fundamental difference is the inability of RT3DE to resolve the separation between trabeculae and myocardium. Indeed, including the trabecular region outside of the blood pool during cMRI contouring in the blood pool significantly reduced the RT3DE vs. cMRI bias, as well as the limits of agreement [110]. This fact sums up with the blurring effect caused by the PSF of the acquired ultrasound signal, which pushes the apparent blood-tissue interface towards the blood pool, as shown by Mor-Avi et al. in balloon phantoms.

More recently, a shift towards more advanced software suites has enabled more automated analysis of RT3DE data, allowing a more efficient workflow towards the extraction of clinically relevant information from RT3DE data. Indeed, the previously cited studies have mostly focused on semiautomatic software tools that provide at most computeraided manual delineation of the LV cavity. Typical time of analysis ranged from around $2 \mathrm{~min}$. [101] to $10 \mathrm{~min}$. [76,118], although several studies report analysis times around 5 min per dataset $[110,122]$. Note that Jacobs et al. have shown that online LV volumetric analysis can provide accurate results in less than 2 minutes per volume [101] but they stress that manual adjustments were required in $42 \%$ of the analyzed cases using an online quantification tool, increasing the analysis time from 2 minutes to up to 5 minutes per volume.

With this in mind, strong research effort has been directed towards more efficient software packages, incorporating advanced computer algorithms enabling a faster, more efficient and more accurate processing of RT3DE volumes. Hansegard et al. [124] and Muraru et al. [125] used GE's AutoLVQ and TomTec's 4D LV-Analysis ${ }^{\odot}$ to show that a more advanced, automated software package can reduce the average time of analysis when compared with standard semi-automated strategies, while keeping comparable accuracy. Muraru et al. [125] has equally shown that fully automated (i.e. only manual initialization on ED and ES frames, with subsequent automatic delineation) is feasible. However, their results show that a noticeable increased agreement can be achieved by manually adjusting the results from an automated method, at the cost of doubling the total analysis time. Kleijn et al. have validated another highly automated software tool, Toshiba's 3D-WMT [126]. Despite only moderately good results for the LV volume assessment, the $\mathrm{EF}$ results showed excellent correlation and remarkably low bias and limits of agreement, indicating that more advanced tracking methods can positively influence the quality of the extracted surfaces when compared to pure contour-extraction approaches. Similar results have been reported by Kawamura et al. [105]. To test the potential of RT3DE in a realistic clinical scenario, Miller et al. analyzed 60 consecutive patients to determine the effect of image quality in RT3DE volume quantification performance [127]. Despite reporting lower agreement with cMRI measurements than previously found, the authors stress that the degree of error is intrinsically linked with image quality. 
Using Siemens' eSie LVA ${ }^{\mathrm{TM}}$ tool, Thavendiranathan et al. demonstrated that fully automatic analysis of RT3DE is possible and presents extremely encouraging results [128]. Note that Thavendiranathan et al. point out that the patients undergoing RT3DE exams in the analyzed dataset were selected for good acoustical windows, thus holding good imaging quality. The authors have applied the same computational automatic analysis algorithm to the reconstructed cMRI datasets and have found slightly higher bias and limits of agreement against the manual delineation on cMRI data than when using the same software on RT3DE data $(-0.8 \pm 4.7 \%$ vs. $-0.3 \pm 2.5 \%)$. This seems to point towards the excellent image quality of the analyzed RT3DE dataset. Similar results have also been published by Zhang et al. [129]. Using the same tool, Chang et al. [130] reported slightly lower correlations and the Bland-Altman analysis on EF estimates revealed much larger bias and limits of agreement than reported by Thavendiranathan et al. in [128]. Nonetheless, it is important to stress that the dataset corresponded to consecutive patients, although previously selected based on 2D echo image quality and the user was allowed to manually correct the automatically detected contours. It should also be noticed that Chang et al. report that automatic results were considered excellent in $11 \%$ of the cases (i.e. not requiring any adjustment), good (i.e. five or fewer manual corrections required) in $34 \%$ of the cases and it failed completely (i.e. required manual delineation) in $10 \%$ of the cases. Regarding the influence of manual correction, Shibayama et al. have evaluated the same system, performing firstly fully automatic analysis and then allowing the user to proceed to manual corrections, in a cohort of 44 consecutive patients [131]. Their results reinforce the findings of Muraru et al. for a different system, thus highlighting that even state-of-the-art software packages are not yet able to consistently perform fully automated/automatic analysis of RT3DE data. Indeed, Shibayama et al. show that fully automatic results are significantly improved through manual interaction. Nonetheless, manual correction increased the total analysis time by a factor of 10 . Using Philips' HeartModel ${ }^{\mathrm{AI}}$ tool, Tsang et al. have analyzed 46 patients achieving similar results to those reported with other fully automatic approaches without performing manual correction of the contours [132].

The key summary of the literature on the clinical validation of RT3DE volumetric assessment against cMRI can also be appreciated in the recent meta-analysis studies of Shimada and Shiota [133] and by Dorosz et al. [134]. Shimada and Shiota's meta-analysis included 3055 subjects in 95 studies, focusing not only on 2D matrix transducers but also earlier systems based on mechanical steering. A key evidence is the significant underestimation bias of left ventricular volumes (both EDV and ESV) by RT3DE compared with cMRI. On the other hand, no statistically significant bias for estimation of EF was found. Sources of error included gender and presence of congenital heart disease, which were associated with more underestimation in the analysis. Semi-automatic border detection and the use of matrix-array transducers were associated with less underestimation. As key conclusion, the studied literature supports the role of RT3DE as both accurate and reproducible in assessing left ventricular volumes and EF, although it is not interchangeable with other radiologic modalities. On the meta-analysis study by Dorosz et al., also an additional perspective on how RT3DE compares with conventional $2 \mathrm{D}$ echocardiography is given in parallel to the central comparison of RT3DE-derived volumetric indices against cMRI. Their main conclusion is that RT3DE underestimates volumes and has wide limits of agreement, but compared with traditional 2D methods, it is more accurate (i.e. smaller bias) for volumes (EDV and ESV) and more precise (i.e. tighter limits of agreement) for EDV, ESV and EF measurements. One of the key benefits of RT3DE is the reduction in intra/interobserver variability, which is important for clinical practice, since disease progression in a patient will be most likely assessed serially by different readers. Dorosz et al. also highlight the natural influence of image quality on the estimation of LV volumetric indices. Indeed, an analysis of those studies that accepted all 3D datasets, instead of selecting patients for image quality, shows that the $95 \%$ limits of agreement against cMRI raise from \pm 34 to $\pm 38 \mathrm{ml}$ for EDV, \pm 30 to $\pm 34 \mathrm{ml}$ for ESV and \pm 12 to $\pm 15 \%$ for $\mathrm{EF}$.

At last, the first step towards effective clinical integration of 3D echo volume measurements is the population-based assessment of normal values, as acknowledged recently by Marwick in the editorial note of a leading cardiovascular imaging journal [135]. Several studies, including the work of Aune et al. [136], Kaku et al. [137], Fukuda et al. [138], Chahal et al. [139] and Muraru et al. [140], have been filling this gap, providing clinicians one of the last pieces of the path towards clinical integration of RT3DE examination in daily routine. An ongoing large-scale project (EchoNoRMAL) is aiming to define the echocardiographic normal ranges of the $\mathrm{LV}$, through a collaborative effort meta-analysis approach [141,142].

\subsection{Left Atrium}

\subsubsection{Available Technology}

Given the low priority given to LA volume and function assessment, the solutions dedicated to LA segmentation are limited. TomTec was the first to commercialize a dedicated tool: 4D LA-Analysis ${ }^{\odot}$. Similarly to an earlier version of TomTec's 4D LV-Analysis ${ }^{\odot}$, the user is asked to manually contour the endocardium in three different views (2-, 3- and 4-chamber) at both ED and ES frames. A polyhedral mesh is then generated for each of those frames by volumetric interpolation of the $2 \mathrm{D}$ contours and temporal smoothing is performed, resulting in a smooth volume curve for the whole cardiac cycle. The mesh volume calculation excludes the mitral valve tenting volume, whose limit is that defined by the mitral valve points introduced by the user. The user can also manually adjust the segmentation results $[143,144]$. This same tool is also available under TomTec's software solution 4D LA-Function ${ }^{\odot}$.

Until recently, no other dedicated tool was available besides TomTec's. Philips' fully automatic HeartModel ${ }^{\mathrm{AI}}$ tool, released on August 2015, will change that, as it also provides LA volumes besides LV (cf. Section 4.1.1.) [103]. 
Table 1. Literature Overview: Validation of RT3DE and commercial software tools for LV volumetric assessment (\#: number of exams; Ref: reference measurements taken from cMRI or manual contouring of RT3DE data (3DM); r: correlation coefficient; BA Bland-Altman analysis).

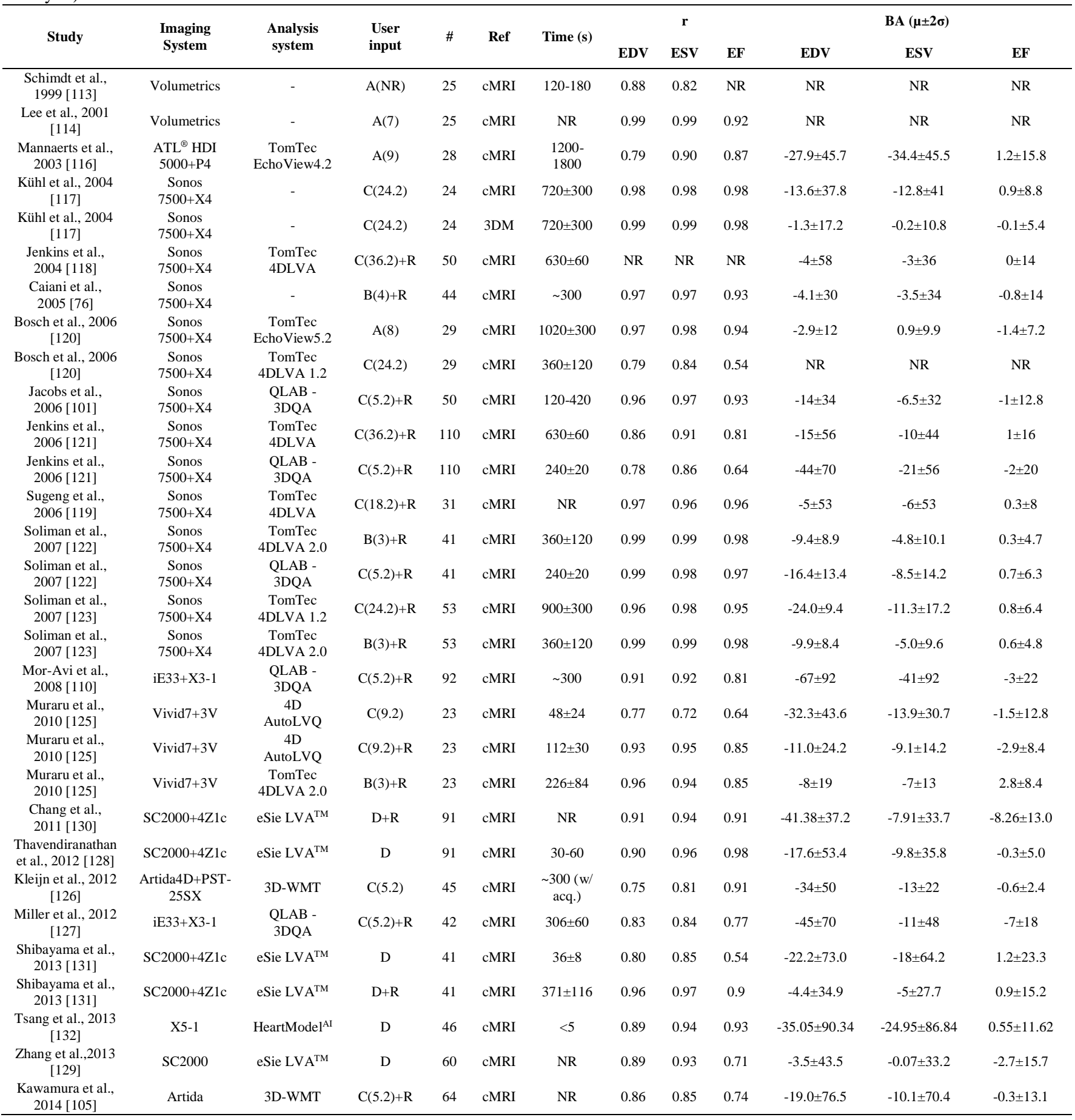

User input: $\mathrm{A}(\mathrm{X})$ : Computer assisted delineation of the 3D surface via manual contouring of $\mathrm{X}$ 2D planes; $\mathrm{B}(\mathrm{X})$ : Semi-automatic segmentation, with manual initialization by contouring in X 2D planes; $C(L, F)$ : Automated segmentation, with user input of L anatomical landmarks in F time frames; D: Fully automatic segmentation without any user intervention; R: Manual refinement of segmentation results. 
Apart from these tools, other LA quantification solutions still rely on the use of generic tools, primarily designed for LV volumetric quantification. With this regard, the use of QLAB - 3DQA (Philips) [102,145,146], and 3DWMT (Toshiba) [102], and eSie LVA ${ }^{\mathrm{TM}}$ (Siemens) [147] for quantification of LA volume has been reported. The description of aforementioned tools can be found in Section 4.1.1.. The current eSie LVA $^{\mathrm{TM}}$ fully automated solution is based on the database-driven knowledge-based approach, which relies on learned features from LV shape, appearance and motion. As such, it seems to not be suited for LA volume analysis. However, a semi-automated version was available and has been used for LA volume assessment [147].

\subsubsection{Validation Efforts}

The recent efforts towards clinical validation of $3 \mathrm{D}$ echocardiographic assessment of LA volumes have been reflected in the latest Recommendations for Chamber Quantification [148]. A summary of the validation studies found in literature are presented in this section and Table 2 presents the corresponding results. Figure 3 shows an LA segmentation example on a 3D echocardiography image.

To et al. [6] address the strengths and weaknesses of different imaging modalities (2D and 3D echocardiography, cMRI and CT) in the assessment of LA morphology and function. In this review, 3D echocardiography is considered comparable to the other modalities regarding the estimation of static dimensions, and superior in the estimation of phasic size, and LA mechanics. In addition, the authors note the current indications of echocardiography for LA assessment (first-line diagnostic evaluation and follow-up) and other potential indications (serial monitoring and detailed functional assessment of LA phasic function).

Miyasaka et al. [145] demonstrated the added value of 3D echocardiography to derive LA volumes, in a study including 57 patients, with multi-detector CT as goldstandard. The volume underestimation typically observed in echocardiographic measurements was significantly lower for LAmax volumes derived from 3D echocardiography, compared to those estimated from 2D echocardiography. Rohner et al. conducted a similar study using TomTec's 4D LA-Function $^{\odot}$ also showing good correlation between CT and RT3DE values [149]. The underestimation of volumes was in this study, however, much larger. A multicenter study (92 patients with a large range of LA volumes) conducted by Mor-Avi et al. [143] showed that LAmin and LAmax volumes from 3D echocardiography also correlate better with cMRI, compared to 2D. Moreover, statistically significant underestimation of volumes was observed on 2D and not on 3D measurements. In the same study, 3D echocardiography also improved classification of enlarged atria, while intra- and inter-observer variability was similar. The volumetric measurements reported in this study were obtained using the semi-automated 4D LA-Function ${ }^{\odot}$ tool (Tomtec).

An extensive analysis of different techniques to derive LA volumes from echocardiography (both 2D and 3D) is presented in [146], including data from 60 patients. The 3D images were analyzed with two semi-automatic tools: TomTec's 4D LA-Analysis ${ }^{\odot}$ and Philips' QLAB - 3DQA, which was built primarily for LV segmentation. Although all volumes derived from echocardiography were underestimated compared to cMRI, reported bias ranged from $-50.5 \%$ down to $-4.7 \%$ across the different techniques. The following techniques estimated LAmax and LAmin volumes with increasing accuracy (sorted from the highest to the lowest bias): 2D prolate ellipsoid method; 3D semiautomated generic tool (QLAB - 3DQA); 2D area-length method; 2D bi-plane Simpson method; 3D manual specific tool (4D LA-Analysis ${ }^{\circledR}$ ). These results suggest that, despite the previously shown importance of 3D data, the accuracy may vary significantly depending on the methodology (semiautomated vs. manual or generic vs. LA-specific tools).

Another study using a generic semi-automated tool, eSie LVA $^{\mathrm{TM}}$, to assess LA volumes from 3DE shows alarmingly inaccurate results [147]. It must be noted however that this study included only atrial fibrillation patients, which are typically more challenging to image and analyze, and that this tool was primarily designed for LV segmentation. Therefore, image quality played a very important role on such results (poor correlation with CT for both 2D and 3D echocardiography measurements). Nonetheless, LA volume was also significantly underestimated in a sub-group of recordings with good image quality ( $-44 \%$ for $2 \mathrm{DE}$ and $-21 \%$ for $3 \mathrm{DE})$.

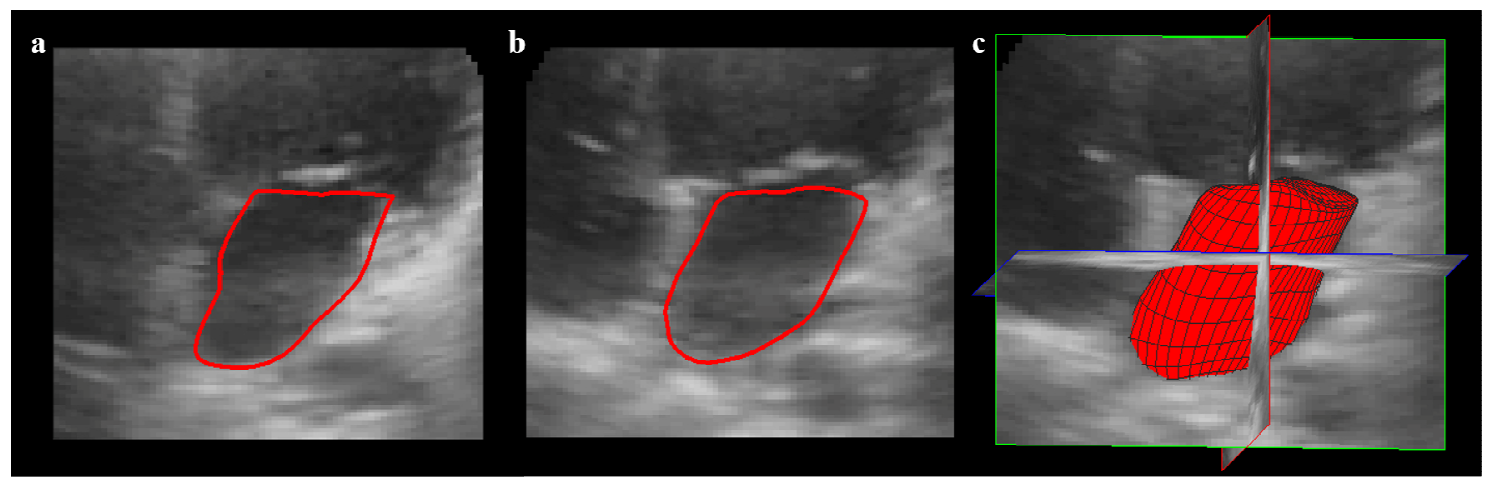

Figure 3. LA segmentation example in a 3D echocardiography image using a semi-automated algorithm [150]. a and b: long axis views; c: triplane-view and 3D rendering. 
Finally, a comparison between two standard echoanalysis tools, QLAB - 3DQA (Philips) and 3D-WMT (Toshiba), was performed in a large study including 120 subjects (both unselected patients and healthy volunteers) [102]. The results were in close agreement for both LAmax and LAmin, and showed equally good inter- and intra-user reproducibility, suggesting its interchangeability. It should be noted however that this refers only to the comparison of echo-based measurements, without an independent modality as reference.

The use of LA-specific fully automatic tools has been reported in a single validation study by Tsang et al. using Philips' HeartModel ${ }^{\mathrm{AI}}$ tool. The results are promising, showing good correlation with volumes obtained from cMRI though somewhat below the performance reported for other LA dedicated semi-automatic tools [132].

In summary, echocardiography is a reliable modality for LA volume assessment (albeit its typical underestimation compared to CT or cMRI). Volume measurements from 3D echocardiography are consistently more accurate and less user-dependent than those from $2 \mathrm{D}$ as pointed out in the recommendations by Lang et al. [148]. Image quality and LA-specificity of automated tools are important factors influencing the reliability of the measurements. LA phasic function assessment from 3D echocardiography still lacks validation, despite having been used in some clinical studies.

Table 2. Literature Overview: Validation of RT3DE and commercial software tools for LA volumetric assessment (\#: number of exams; Ref: reference measurements taken from cMRI or manual contouring of RT3DE data (3DM); r: correlation coefficient; BA Bland-Altman analysis).

\begin{tabular}{|c|c|c|c|c|c|c|c|c|c|c|c|c|}
\hline \multirow{2}{*}{ Study } & \multirow{2}{*}{$\begin{array}{c}\text { Imaging } \\
\text { System }\end{array}$} & \multirow{2}{*}{$\begin{array}{c}\text { Analysis } \\
\text { system }\end{array}$} & \multirow{2}{*}{ User input } & \multirow{2}{*}{$\#$} & \multirow{2}{*}{ Ref } & \multirow{2}{*}{$\begin{array}{c}\text { Time } \\
\text { (s) }\end{array}$} & \multicolumn{3}{|c|}{$\mathbf{r}$} & \multicolumn{3}{|c|}{ BA $(\mu \pm 2 \sigma)$} \\
\hline & & & & & & & LAmax & LAmin & $\mathrm{EF}$ & LAmax & LAmin & $\mathrm{EF}$ \\
\hline $\begin{array}{c}\text { Miyasaka et al., } \\
2011[145]\end{array}$ & $\mathrm{iE} 33+\mathrm{X} 3-1$ & QLAB - 3DQA & $\mathrm{C}(5,2)+\mathrm{R}$ & 57 & $\mathrm{CT}$ & $300-600$ & 0,95 & NR & NR & $-2.5 \pm 3.6$ & NR & NR \\
\hline $\begin{array}{c}\text { Rohner et al., } 2011 \\
\text { [149] }\end{array}$ & $\mathrm{iE} 33+\mathrm{X} 3-1$ & $\begin{array}{l}\text { TomTec } \\
\text { 4DLAF }\end{array}$ & $\mathrm{B}(3)$ & 34 & $\mathrm{CT}$ & NR & 0.92 & 0.95 & 0.82 & $-24.8 \pm 40.6$ & $-25.2 \pm 39.0$ & $8.6 \pm 18.4$ \\
\hline $\begin{array}{c}\text { Mor-Avi et al., } 2012 \\
\text { [143] }\end{array}$ & $\mathrm{iE} 33+\mathrm{X} 3-1$ & $\begin{array}{l}\text { TomTec } \\
\text { 4DLAF }\end{array}$ & $\mathrm{B}(3)$ & 92 & cMRI & NR & 0.93 & 0.88 & NR & $-1 \pm 28$ & $0 \pm 43$ & NR \\
\hline $\begin{array}{c}\text { Buechel et al., } 2013 \\
\text { [144] }\end{array}$ & $\begin{array}{c}\mathrm{iE} 33+\mathrm{X} 3- \\
1 / \mathrm{X} 5-1\end{array}$ & $\begin{array}{l}\text { TomTec } \\
\text { 4DLAA }\end{array}$ & $\mathrm{B}(3)$ & 55 & cMRI & NR & 0.93 & 0.95 & 0.92 & $-7.2 \pm 21.8$ & $-7.2 \pm 20.0$ & $1.8 \pm 17.7$ \\
\hline $\begin{array}{c}\text { Buechel et al., } 2013 \\
\text { [146] }\end{array}$ & $\begin{array}{c}\mathrm{iE} 33+\mathrm{X} 3- \\
1 / \mathrm{X} 5-1\end{array}$ & $\begin{array}{l}\text { TomTec } \\
\text { 4DLAA }\end{array}$ & $\mathrm{B}(3)$ & 60 & cMRI & $161 \pm 29$ & 0.94 & 0.95 & NR & $-5 \pm 24$ & $-6.5 \pm 20$ & NR \\
\hline $\begin{array}{c}\text { Buechel et al., } 2013 \\
\text { [146] }\end{array}$ & $\begin{array}{c}\text { iE33+X3- } \\
1 / \mathrm{X} 5-1\end{array}$ & QLAB - 3DQA & $\mathrm{C}(5,2)+\mathrm{R}$ & 60 & cMRI & $144 \pm 19$ & 0.80 & 0.90 & NR & $-17 \pm 33$ & $-11 \pm 27$ & NR \\
\hline $\begin{array}{c}\text { Tsang et al., } 2013 \\
\text { [132] }\end{array}$ & $\mathrm{X} 5-1$ & HeartModel $^{\mathrm{AI}}$ & $\mathrm{D}$ & 46 & cMRI & $<5$ & 0.91 & NR & NR & $-10.26 \pm 32.30$ & NR & NR \\
\hline $\begin{array}{c}\text { Heo et al., } 2014 \\
{[147]}\end{array}$ & SC2000 & eSie LVA ${ }^{\mathrm{TM}}$ & NR & 31 & $\mathrm{CT}$ & NR & 0.23 & NR & NR & NR & NR & NR \\
\hline
\end{tabular}

User input: $\mathrm{A}(\mathrm{X})$ : Computer assisted delineation of the 3D surface via manual contouring of $\mathrm{X}$ 2D planes; $\mathrm{B}(\mathrm{X})$ : Semi-automatic segmentation, with manual initialization by contouring in X 2D planes; C(L,F): Automated segmentation, with user input of L anatomical landmarks in F time frames; D: Fully automatic segmentation without any user intervention; R: Manual refinement of segmentation results.

\subsection{Right Ventricle}

\subsubsection{Available Technology}

Recently, Tomtec Imaging Systems (Unterschleissheim, Germany) has made available an offline tool for semi-automatic RV function assessment, 4D RVFunction $^{\odot}$ [151]. Firstly, the correct anatomical axis must be defined by the user and landmarks placed in both the tricuspid and mitral valves and the apex. The end-diastolic and end-systolic phases must then be identified and the endocardial borders manually contoured on the 4-chamber, sagittal and coronal views on both phases. The software then automatically delineates the RV endocardial border along the heart cycle. The results can be refined by the user at the end of this step. A number of measurement values are then available for the user namely $3 \mathrm{D}$ volume measurements (RV EDV, ESV, EF and SV), strain analysis and 2D standard measurements [151]. Both GE Vingmed and Siemens Medical Solutions have recently made this tool available in their systems thanks to a strategic cooperation with TomTec
Imaging Systems. Figure 4 shows an in-program screenshot of $4 \mathrm{D}$ RV-Function ${ }^{\odot}$ in the contour revision step.

Ventripoint Diagnostics Ltd. (Bellevue, United States) has introduced the Ventripoint Medical System ${ }^{\mathrm{TM}}$ [152]. This system relies on a $3 \mathrm{D}$ RV reconstruction from a freehand acquisition using a standard 2D probe with a magnetic localizing system. After acquisition of sufficient $2 \mathrm{D}$ planes for a good coverage of the RV (10 to 15 views) the end-diastolic phase is automatically defined according to the electrocardiographic $\mathrm{R}$ wave and the end-systolic phase is defined manually by the user. An offline analysis is then required, namely the identification of anatomic landmarks (ideally 17 to 23 points) after which a database of 3D RV shapes is used to define the RV shape using a piecewise smooth subdivision surface reconstruction [152]. 


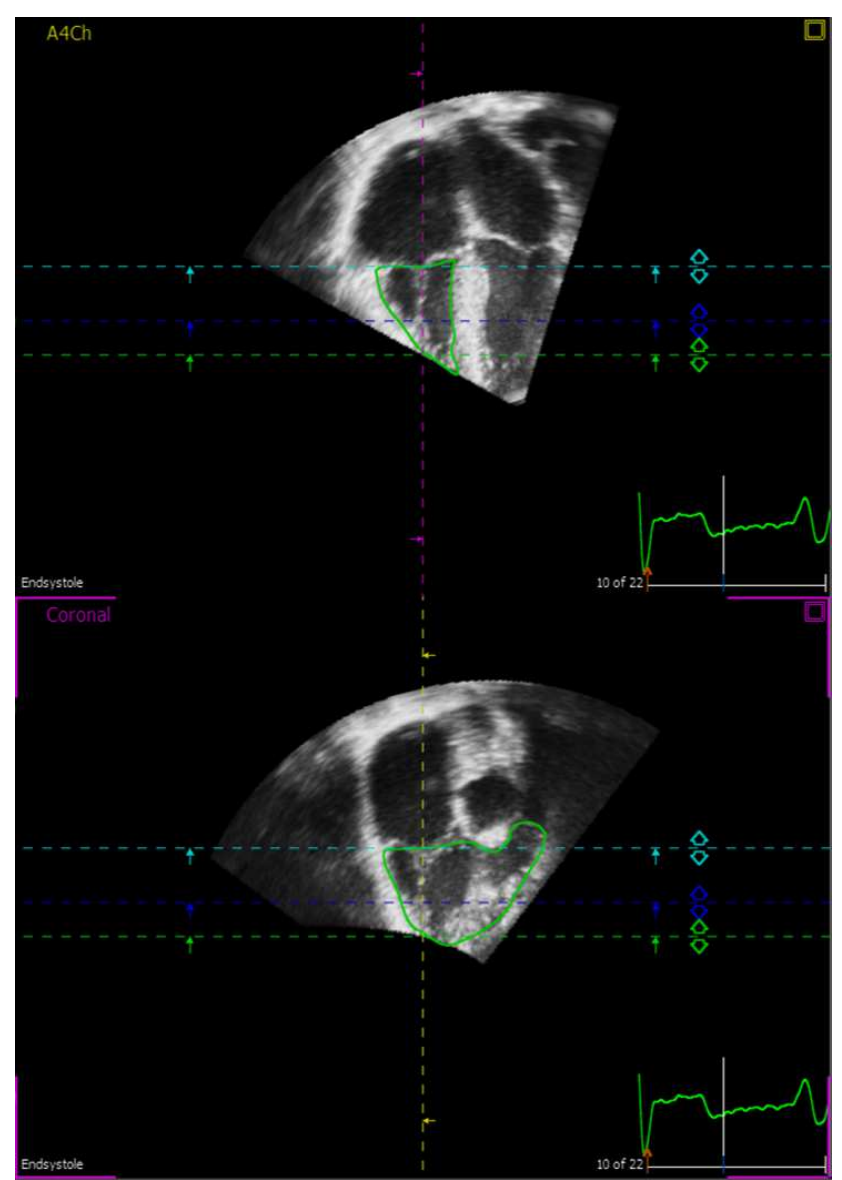

Figure 4. TomTec 4D RV-Function ${ }^{\odot}$ screenshot (Courtesy of Guido Claessen, Laboratory on Cardiovascular Imaging and Dynamics, KU Leuven, Belgium).

\subsubsection{Validation Efforts}

Though the importance of assessing RV function assessment has long been recognized, the lack of literature found for RV segmentation in echocardiography is striking, especially when compared to the extensive literature found for the LV. This can be justified by a series of different factors. First of all, the very acquisition of the RV is often quite challenging in $3 \mathrm{DTE}$ due to its position and shape [153]. The sternum and lung tissue can shadow the imaging of the RV anterior wall and outflow tract and an attempt to avoid this shadowing frequently results in part of the anterior wall not being included in the field of view [154]. Secondly, the anatomical complexity and asymmetric shape of the RV make an automatic segmentation an extremely challenging task. The heavy trabeculation found in the RV and the thin myocardial wall can also increase the difficulty when assessing the volume [155]. Finally, the perceived greater importance of the left heart has forced most research to be directed towards LV and LA segmentation, thus demoting $\mathrm{RV}$ analysis to a field of study of lesser importance. In this section some of the studies focused on the validation of RV volume assessment by $3 \mathrm{D}$ echocardiography are summarized and Table 3 show the corresponding results.

The first efforts for RV volume/function assessment were, of course, developed for 2D echocardiography. An example of this is the tricuspid annular plane systolic excursion (TAPSE) introduced by Kaul et al. [156]. This measure extracted from a 4-chamber view is shown to correlate to $\mathrm{RV}$ volumes obtained from radionuclide angiography and is still common in today's clinical practice [148]. Nevertheless, Helbing et al. have shown, by comparison with cMRI volumes, that due to the asymmetrical shape of the RV, 2D echocardiography is not sufficient to assess the RV volumes [157]. Gopal et al. go a step further by comparing volumes assessed through manual contouring of 3DTE images of the RV with 2D estimated volumes and volumes determined by cMRI, concluding that $3 \mathrm{D}$ echocardiography is superior to $2 \mathrm{D}$ for $\mathrm{RV}$ volume assessment [158]. Two studies, by Jenkins et al. and van der Zwaan et al., compare once more 2D and 3D echocardiography to cMRI for RV volume assessment though now using 4D RV-Function ${ }^{\odot}$ to determine the 3D RV volumes $[159,160]$. Both studies are in agreement that RT3DE not only is superior to the two-dimensional methods but also has a greater reproducibility. A single study by Kjaergaard et al. claims that 3D echocardiography brings no advantage from 2D when compared to cMRI assessed volumes [161]. Later studies however propose that this conclusion is merely a result of the older $3 \mathrm{D}$ echocardiographic platform used and the population chosen [160].

In a compromise between 2D and 3D echocardiography, some authors have used 3D reconstruction of $2 \mathrm{D}$ echocardiographic planes to image the whole shape of the RV. Linker et al. have used 3D reconstruction of $2 \mathrm{D}$ images of ex vivo hearts to manually contour the RV endocardium [162]. This was shown to correlate with the reference volume obtained by measuring the volume of water required to fill the RV. The 3D reconstruction system commercialized by Ventripoint Diagnostics Ltd. is compared in two clinical studies to RV volumes obtained by cMRI showing a good correlation between the two [152,163].

The accuracy of manual contouring of the RV in the 3D echocardiography has been validated in a number of different frameworks but the gold standard for RV volume assessment remains cMRI. Some of the approaches include models from excised animal or human hearts [37,164-168], in vivo measurement by intracavity balloon [169], thermodilution [170] and intraoperative measurements using injections of saline solution [171]. Comparisons of manual contouring of the $\mathrm{RV}$ in $3 \mathrm{D}$ echocardiography are also numerous. The first effort for validation of $\mathrm{RV}$ manual contouring against cMRI was conducted by Vogel et al. using a rotating one-dimensional array probe and performing manual contouring in parallel planes along the long axis [172]. Similar studies were published by Fujimoto et al. [173] and Papavassiliou et al. [174] all with good correlation values between 3D echocardiography and cMRI. Prakasa et al. performed the first validation of $\mathrm{RV}$ manual contouring in full matrix transducer imaging using both a Sonos 7500 and a Philips iE33 [175]. The manual contouring was performed in only two orthogonal long axes planes which accounts for the low correlation values obtained and large bias, especially for EDV. In a study by Nesser et al., RV manual contouring was compared to cMRI in both transthoracic (TTE) and transesophageal (TEE) acquisitions [176]. Manual contouring was done in this study in 10 to 12 azimuthally equidistant planes. Results highlight better correlation and 
bias for the TEE approach which are explained by the better image quality. However, the TTE approach also presents very competitive values. Lu et al. have used TomTec's 4D Echo-View tool to perform manual contouring of the RV in $5 \mathrm{~mm}$ contiguous planes and compared the volumes obtained to cMRI reference also with good results [177].

The validation of the semi-automatic method 4D RVFunction $^{\odot}$ developed by TomTec Imaging Systems has also been a subject of some attention and has been compared against cMRI RV volumes in some studies. A first effort was performed by Niemann et al. using a prototype of the 4D RV-Function ${ }^{\circledR}$ tool which depended on a single manual contouring in one plane [178]. The software then reconstructed the contours in the orthogonal planes and manual refinement could then take place. Results show good correlation for the RV volumes against manual contouring of cMRI volumes although the $\mathrm{EF}$ results are not so competitive. Niemann et al. also used the prototype 4D RVFunction $^{\odot}$ to contour the cMRI images obtaining excellent correlation, bias and limits of agreement. The actual 4D RVFunction $^{\odot}$ tool was validated against cMRI by Grewal et al. obtaining good correlation values [179] but also by van der Zwaan et al. [151], Leibundgut et al. [180] and Zhang et al. [181]. In spite of presenting good correlation values, the results from van der Zwaan et al. are the most striking by revealing the severe underestimation of the RV volumes by
3D echocardiography. Finally, Ostenfeld et al. have used the same commercial tool with and without performing manual refinement after the semi-automatic contouring and compared the obtained RV volumes against cMRI [154]. Besides again evidencing the volume underestimation that results from 3D echocardiography, and similarly to what was shown by Shibamaya et al. for the LV commercial approaches, Ostenfeld at al. show that manual correction is still necessary for better results to be achieved.

In regard to the reference values for RV volumes, several studies have published values in different populations. Gopal et al. [158] presented a study of the normal RV volumes performed in 71 healthy patients using manual contouring and disk summation. Tamborini et al. [182] studied 245 subjects divided by age and gender performing the contouring using TomTec's 4D RVFunction $^{\odot}$ tool. A more extensive study was conducted by Maffessanti et al. including 540 healthy adults again using the tool by TomTec for semi-automatic contouring and reporting age-, body size- and sex-specific reference values for RV volumes and RV EF [183].

\subsection{Right Atrium}

To the best knowledge of the authors, there is at this point no commercial solution or validation studies for automatic or semi-automatic RA volume assessment.

Table 3. Literature Overview: Validation of RT3DE and commercial software tools for RV volumetric assessment (\#: number of exams; Ref: reference measurements taken from cMRI or manual contouring of RT3DE data (3DM); r: correlation coefficient; BA Bland-Altman analysis).

\begin{tabular}{|c|c|c|c|c|c|c|c|c|c|c|c|c|}
\hline \multirow{2}{*}{ Study } & \multirow{2}{*}{$\begin{array}{c}\text { Imaging } \\
\text { System }\end{array}$} & \multirow{2}{*}{$\begin{array}{c}\text { Analysis } \\
\text { system }\end{array}$} & \multirow{2}{*}{$\begin{array}{l}\text { User } \\
\text { input }\end{array}$} & \multirow{2}{*}{ \# } & \multirow{2}{*}{ Ref } & \multirow{2}{*}{$\underset{(s)}{\text { Time }}$} & \multicolumn{3}{|c|}{$\mathbf{r}$} & \multicolumn{3}{|c|}{ BA $(\mu \pm 2 \sigma)$} \\
\hline & & & & & & & EDV & ESV & $\mathrm{EF}$ & EDV & ESV & $\mathrm{EF}$ \\
\hline $\begin{array}{c}\text { Vogel et al., } \\
1997 \text { [172] }\end{array}$ & Vingmed 800 & - & $\mathrm{A}(2 \mathrm{~mm})$ & 16 & cMRI & NR & 0.95 & 0.751 & NR & NR & NR & NR \\
\hline $\begin{array}{c}\text { Fujimoto et al., } \\
1998 \text { [173] }\end{array}$ & $\begin{array}{c}\text { SSH160A+486 } \\
\text { CPU }\end{array}$ & - & $\mathrm{A}(2 \mathrm{~mm})$ & 15 & $\mathrm{cMRI}$ & NR & 0.94 & 0.97 & 0.90 & NR & NR & NR \\
\hline $\begin{array}{l}\text { Papavassiliou et } \\
\text { al., } 1998 \text { [174] }\end{array}$ & Sonos 2500 & - & $\begin{array}{c}\mathrm{A}(3- \\
3.5 \mathrm{~mm})\end{array}$ & 13 & cMRI & NR & 0.95 & 0.95 & 0.8 & $-9.6 \pm 31.0$ & $-4.3 \pm 27$ & $-3.9 \pm 14.6$ \\
\hline $\begin{array}{l}\text { Prakasa et al., } \\
2006 \text { [175] }\end{array}$ & $\begin{array}{c}\text { Sonos } 7500 / \mathrm{iE} 3 \\
3\end{array}$ & TomTec & $\mathrm{A}(2)$ & 43 & cMRI & NR & 0.5 & 0.72 & 0.88 & $-15.9 \pm 35.6$ & $-6.8 \pm 17.8$ & NR \\
\hline $\begin{array}{c}\text { Nesser et al., } \\
2006 \text { [176] }\end{array}$ & $\begin{array}{c}\text { CFM800 } \\
\text { (TTE) }\end{array}$ & - & $\begin{array}{c}\mathrm{A}(10- \\
12)\end{array}$ & 20 & cMRI & NR & 0.85 & 0.86 & 0.86 & $-1.6 \pm 36.4$ & $0.1 \pm 26.8$ & $-2.0 \pm 18.8$ \\
\hline $\begin{array}{c}\text { Nesser et al., } \\
2006 \text { [176] }\end{array}$ & $\begin{array}{l}\text { CFM800 } \\
\text { (TEE) }\end{array}$ & - & $\begin{array}{c}\mathrm{A}(10- \\
12)\end{array}$ & 20 & cMRI & NR & 0.86 & 0.88 & 0.84 & $-1.3 \pm 35.6$ & $2.8 \pm 30.4$ & $-4.0 \pm 19.4$ \\
\hline $\begin{array}{l}\text { Niemann et al., } \\
2007 \text { [178] }\end{array}$ & Sonos 7500 & $\begin{array}{c}\text { TomTec } \\
\text { 4DRV } \\
\text { prototype }\end{array}$ & $B(1)+R$ & 30 & cMRI & 600 & 0.93 & 0.92 & 0.68 & $-0.44 \pm 25.40$ & $1.01 \pm 7.75$ & $-1.56 \pm 13.39$ \\
\hline $\begin{array}{c}\text { Lu et al., } 2008 \\
{[177]}\end{array}$ & Sonos $7500+\mathrm{X} 4$ & $\begin{array}{l}\text { TomTec 4D } \\
\text { EchoView }\end{array}$ & $\mathrm{A}(5 \mathrm{~mm})$ & 17 & $\mathrm{cMRI}$ & NR & 0.98 & 0.96 & 0.89 & $-7.0 \pm 18.0$ & $-3.2 \pm 14.2$ & $0.3 \pm 8.2$ \\
\hline $\begin{array}{c}\text { Grewal et al., } \\
2010 \text { [179] }\end{array}$ & iE33 & $\begin{array}{l}\text { TomTec } \\
\text { 4DRVF }\end{array}$ & $B(3)+R$ & 25 & $\mathrm{cMRI}$ & NR & 0.88 & 0.89 & 0.89 & NR & NR & NR \\
\hline $\begin{array}{l}\text { Leibundgut et } \\
\text { al., } 2010[180]\end{array}$ & $\mathrm{iE} 33+\mathrm{X} 3-1$ & $\begin{array}{l}\text { TomTec } \\
\text { 4DRVF }\end{array}$ & $B(3)+R$ & 88 & cMRI & NR & 0.84 & 0.83 & 0.72 & $-10.2 \pm 21.6$ & $-4.5 \pm 14.8$ & $-0.4 \pm 7.6$ \\
\hline $\begin{array}{c}\text { Van der Zwaan } \\
\text { et al., 2010 } \\
{[151]}\end{array}$ & $\mathrm{iE} 33+\mathrm{X} 3-1$ & $\begin{array}{c}\text { TomTec } \\
\text { 4DRVF4.0 }\end{array}$ & $B(3)+R$ & 50 & cMRI & $126 \pm 30$ & 0.93 & 0.91 & 0.74 & $-34 \pm 66$ & $-11 \pm 56$ & $-4 \pm 13$ \\
\hline $\begin{array}{l}\text { Ostenfeld et al., } \\
2012 \text { [154] }\end{array}$ & $\begin{array}{c}\text { Sonos } 7500+X 4 \\
/ i E 33+X 3-1\end{array}$ & $\begin{array}{l}\text { TomTec } \\
\text { 4DRVF }\end{array}$ & $\mathrm{B}(3)$ & 53 & cMRI & NR & 0.769 & 0.773 & 0.488 & $-32 \pm 52$ & $-8 \pm 34$ & $-6 \pm 18$ \\
\hline $\begin{array}{l}\text { Ostenfeld et al., } \\
2012[154]\end{array}$ & $\begin{array}{c}\text { Sonos } 7500+\mathrm{X} 4 \\
\text { /iE33+X3-1 }\end{array}$ & $\begin{array}{l}\text { TomTec } \\
\text { 4DRVF }\end{array}$ & $B(3)+R$ & 53 & cMRI & NR & 0.779 & 0.835 & 0.597 & $-22 \pm 52$ & $-7 \pm 32$ & $-2 \pm 16$ \\
\hline $\begin{array}{l}\text { Zhang et al., } \\
2013 \text { [181] }\end{array}$ & SC2000+4Z1c & $\begin{array}{l}\text { TomTec } \\
\text { 4DRVF }\end{array}$ & $\mathrm{B}(3)+\mathrm{R}$ & 59 & $\mathrm{cMRI}$ & NR & 0.97 & 0.96 & 0.71 & $-2.16 \pm 15.40$ & $-2.6 \pm 16.12$ & $0.86 \pm 16.32$ \\
\hline
\end{tabular}

User input: $\mathrm{A}(\mathrm{X})$ : Computer assisted delineation of the $3 \mathrm{D}$ surface via manual contouring, where $\mathrm{X}$ is the number of $2 \mathrm{D}$ planes contour or the distance between parallel 2D planes contoured; $\mathrm{B}(\mathrm{X})$ : Semi-automatic segmentation, with manual initialization by contouring in X 2D planes; C(L,F): Automated segmentation, with user input of L anatomical landmarks in F time frames; D: Fully automatic segmentation without any user intervention; R: Manual refinement of segmentation results. 


\section{CLOSING REMARKS}

The assessment of cardiac chamber volume is a fundamental task in both clinical and research context to obtain a unique insight into the heart function and has been shown to have a strong diagnostic and prognostic value in numerous instances. Among the different heart imaging modalities, RT3DE reveals itself as an excellent technique as it allows a true three dimensional imaging of the heart while maintaining a relatively low cost and portability and without the need for exposure to ionizing radiation. However, the nature of RT3DE make it a particularly challenging image analysis task. For these reasons, a great effort has been made towards RT3DE image analysis and retrieval of its important clinical information. Semi-automatic approaches are the most common but, recently, attention has been shifting to more automatic ones and special attention is being devoted to implementing these solutions in real-time. The use of prior information and population-based methods are particularly promising with new approaches reaching the field in the last years.

Because most attention has been directed towards the $\mathrm{LV}$, the development of methods for the remaining heart chambers has been more scarce in spite of the fact that the assessment of function of these chambers is of indisputable clinical importance. Nevertheless, the advances already achieved with LV will facilitate the implementation of new methods for these chambers, with methods being transported and adapted from one chamber to the other.

Though not in the scope of this work, the advances with RT3DE image acquisition also play a powerful role in taking this field further. It is expected that, in the future, better image quality will be possible with both higher frame rates and higher spatial resolution. This will not only make cardiac function assessment through RT3DE a more accessible goal but will also give access to new information making RT3DE an even more powerful tool.

In conclusion, it can be expected that the importance of cardiac function assessment by RT3DE will continue to rise as technology evolves and novel, more sophisticated and automated approaches arise in the field making RT3DE an undeniable tool in clinical practice.

\section{REFERENCES}

[1] World Health Organization. Global Status Report On Noncommunicable Diseases 2014. 2014.

[2] Mathers CD, Loncar D. Projections of global mortality and burden of disease from 2002 to 2030. PLoS Med. 2006; 3(11): 2011-30.

[3] Leung KYE, Bosch JG. Automated border detection in threedimensional echocardiography: Principles and promises. Eur J Echocardiogr. 2010; 11(2): 97-108.

[4] Pombo JF, Troy BL, Russell RO. Left ventricular volumes and ejection fraction by echocardiography. Circulation. 1971; 43(4): 480-90.
[10] Risk Stratification and Survival after Myocardial Infarction. N Engl J Med. 1983; 309(6): 331-6.

[11] Rouleau JL, Talajic M, Sussex B, et al. Myocardial infarction patients in the 1990s - Their risk factors, stratification and survival in Canada: The Canadian Assessment of Myocardial Infarction (CAMI) study. J Am Coll Cardiol. 1996; 27(5): 1119-27.

[12] La Rovere MT, Bigger Jr JT, Marcus FI, Mortara A, Schwartz PJ. Baroreflex sensitivity and heart-rate variabiltiy in prediction of total cardiac mortality after myocardial infarction. Lancet. 1998; 351: 478-84.

[13] Exner D V., Kavanagh KM, Slawnych MP, et al. Noninvasive Risk Assessment Early After a Myocardial Infarction. The REFINE Study. J Am Coll Cardiol. 2007; 50(24): 2275-84.

[14] Bauer A, Barthel P, Schneider R, et al. Improved Stratification of Autonomic Regulation for risk prediction in post-infarction patients with preserved left ventricular function (ISAR-Risk). Eur Heart J. 2009; 30(5): 576-83.

[15] Lewis EF, Moye L a., Rouleau JL, et al. Predictors of Late Development of Heart Failure in Stable Survivors of Myocardial Infarction: The CARE Study. J Am Coll Cardiol. 2003; 42(8): 1446-53.

[16] Hallstrom A, Pratt CM, Leon Greene H, et al. Relations between heart failure, ejection fraction, arrhythmia suppression and mortality: Analysis of the Cardiac Arrhythmia Suppression Trial. J Am Coll Cardiol. 1995; 25(6): 1250-7.

[17] Buxton AE, Lee KL, Hafley GE, et al. Limitations of Ejection Fraction for Prediction of Sudden Death Risk in Patients With Coronary Artery Disease. Lessons From the MUSTT Study. J Am Coll Cardiol. 2007; 50(12): 1150-7.

[18] Owan TE, Hodge DO, Herges RM, et al. Trends in prevalence and outcome of heart failure with preserved ejection fraction. N Engl J Med. 2006; 355(3): 251-9.

[19] Bhatia RS, Tu J V, Lee DS, et al. Outcome of heart failure with preserved ejection fraction in a population-based study. $\mathrm{N}$ Engl $\mathrm{J}$ Med. 2006; 355(3): 260-9.

[20] Somaratne JB, Berry C, McMurray JJ V, et al. The prognostic significance of heart failure with preserved left ventricular ejection fraction: A literature-based meta-analysis. Eur J Heart Fail. 2009; 11(9): 855-62. 
[21] Group MG, Failure H. The survival of patients with heart failure with preserved or reduced left ventricular ejection fraction: an individual patient data meta-analysis. Eur Heart J. 2012; 33(14): 1750-7.

[22] Komajda M, Jais JP, Reeves F, et al. Factors predicting mortality in idiopathic dilated cardiomyopathy. Eur Heart J. 1990; 11(9): 824-31.

[23] Rihal CS, Nishimura R a, Hatle LK, Bailey KR, Tajik a J. Systolic and diastolic dysfunction in patients with clinical diagnosis of dilated cardiomyopathy. Relation to symptoms and prognosis. Circulation. 1994; 90(6): 2772-9.

[24] Giannuzzi P, Temporelli PL, Bosimini E, et al. Independent and incremental prognostic value of Doppler-derived mitral deceleration time of early filling in both symptomatic and asymptomatic patients with left ventricular dysfunction. J Am Coll Cardiol. 1996; 28(2): 383-90.

[25] Yamada S, Ishii H, Takahashi H, et al. Prognostic value of reduced left ventricular ejection fraction at start of hemodialysis therapy on cardiovascular and all-cause mortality in end-stage renal disease patients. Clin J Am Soc Nephrol. 2010; 5(10): 1793 8.

[26] Sharir T, Germano G, Kavanagh PB, et al. Incremental prognostic value of post-stress left ventricular ejection fraction and volume by gated myocardial perfusion single photon emission computed tomography. Circulation. 1999; 100(10): 1035-42.

[27] Coletta C, Galati a, Ricci R, et al. Prognostic value of left ventricular volume response during dobutamine stress echocardiography. Eur Heart J. 1997; 18(10): 1599-605.

[28] Tsang TSM, Barnes ME, Gersh BJ, Bailey KR, Seward JB. Left atrial volume as a morphophysiologic expression of left ventricular diastolic dysfunction and relation to cardiovascular risk burden. Am J Cardiol. 2002; 90(12): 1284-9.

[29] Rossi a., Cicoira M, Zanolla L. Determinants and prognostic value of left atrial volume in patients with dilated cardiomyopathy. ACC Curr J Rev. 2003; 12(1): 45-6.

[30] Pritchett AM, Jacobsen SJ, Mahoney DW, et al. Left atrial volume as an index of left atrial size: A population-based study. J Am Coll Cardiol. 2003; 41(6): 1036-43.

[31] Tsang TSM, Abhayaratna WP, Barnes ME, et al. Prediction of cardiovascular outcomes with left atrial size: Is volume superior to area or diameter? J Am Coll Cardiol. 2006; 47(5): 1018-23.

[32] Takemoto Y, Barnes ME, Seward JB, et al. Usefulness of left atrial volume in predicting first congestive heart failure in patients $>$ or $=65$ years of age with well-preserved left ventricular systolic function. Am J Cardiol. 2005; 96(6): 832-6.

[33] Barnes ME, Miyasaka Y, Seward JB, et al. Left atrial volume in the prediction of first ischemic stroke in an elderly cohort without atrial fibrillation. Mayo Clin Proc. United States; 2004 Aug; 79(8): 1008-14.

[34] Leung DY, Chi C, Allman C, et al. Prognostic implications of left atrial volume index in patients in sinus rhythm. Am J Cardiol. Elsevier Inc.; 2010; 105(11): 1635-9.

[35] Ristow B, Ali S, Whooley M a, Schiller NB. Usefulness of left atrial volume index to predict heart failure hospitalization and mortality in ambulatory patients with coronary heart disease and comparison to left ventricular ejection fraction (from the Heart and Soul Study). Am J Cardiol. 2008; 102(1): 70-6.

[36] Moller JE, Hillis GS, Oh JK, et al. Left atrial volume: a powerful predictor of survival after acute myocardial infarction. Circulation. 2003; 107(17): 2207-12.

[37] Beinart R, Boyko V, Schwammenthal E, et al. Long-term prognostic significance of left atrial volume in acute myocardial infarction. J Am Coll Cardiol. 2004; 44(2): 327-34.
[38] Osranek M, Bursi F, Bailey KR, et al. Left atrial volume predicts cardiovascular events in patients originally diagnosed with lone atrial fibrillation: Three-decade follow-up. Eur Heart J. 2005 26(23): 2556-61.

[39] Tsang TSM, Gersh BJ, Appleton CP, et al. Left ventricular diastolic dysfunction as a predictor of the first diagnosed nonvalvular atrial fibrillation in 840 elderly men and women. J Am Coll Cardiol. 2002; 40(9): 1636-44.

[40] Tsang TSM, Barnes ME, Bailey KR, et al. Left atrial volume: important risk marker of incident atrial fibrillation in 1655 older men and women. Mayo Clin Proc. 2001; 76(5): 467-75.

[41] Di Salvo TG, Mathier M, Semigran MJ, Dec GW. Preserved right ventricular ejection fraction predicts exercise capacity and survival in advanced heart failure. J Am Coll Cardiol. 1995; 25(5): $1143-53$.

[42] De Groote P, Millaire a, Foucher-Hossein C, et al. Right ventricular ejection fraction is an independent predictor of survival in patients with moderate heart failure. J Am Coll Cardiol. 1998; 32(4): 948-54.

[43] Bourantas C V., Loh HP, Bragadeesh T, et al. Relationship between right ventricular volumes measured by cardiac magnetic resonance imaging and prognosis in patients with chronic heart failure. Eur J Heart Fail. 2011; 13(1): 52-60.

[44] Ghio S, Gavazzi A, Campana C, et al. Independent and additive prognostic value of right ventricular systolic function and pulmonary artery pressure in patients with chronic heart failure. $\mathrm{J}$ Am Coll Cardiol. 2001; 37(1): 183-8.

[45] Meyer P, Filippatos GS, Ahmed MI, et al. Effects of right ventricular ejection fraction on outcomes in chronic systolic heart failure. Circulation. United States; 2010 Jan; 121(2): 252-8.

[46] Van Wolferen S a., Marcus JT, Boonstra A, et al. Prognostic value of right ventricular mass, volume, and function in idiopathic pulmonary arterial hypertension. Eur Heart J. 2007; 28(10): 12507.

[47] Van de Veerdonk MC, Kind T, Marcus JT, et al. Progressive Right Ventricular Dysfunction in Patients With Pulmonary Arterial Hypertension Responding to Therapy. J Am Coll Cardiol. Elsevier Inc.; 2011; 58(24): 2511-9.

[48] Larose E, Ganz P, Reynolds HG, et al. Right Ventricular Dysfunction Assessed by Cardiovascular Magnetic Resonance Imaging Predicts Poor Prognosis Late After Myocardial Infarction. J Am Coll Cardiol. 2007; 49(8): 855-62.

[49] Juillière Y, Barbier G, Feldmann L, et al. Additional predictive value of both left and right ventricular ejection fractions on longterm survival in idiopathic dilated cardiomyopathy. Eur Heart J. 1997; 18(2): 276-80.

[50] Kang DK, Thilo C, Schoepf UJ, et al. CT signs of right ventricular dysfunction: Prognostic role in acute pulmonary embolism. JACC Cardiovasc Imaging. Elsevier Inc.; 2011; 4(8): 841-9.

[51] Sallach J a., Tang WHW, Borowski AG, et al. Right Atrial Volume Index in Chronic Systolic Heart Failure and Prognosis. JACC Cardiovasc Imaging. American College of Cardiology Foundation; 2009; 2(5): 527-34

[52] Bellenger NG, Burgess MI, Ray SG, et al. Comparison of left ventricular ejection fraction and volumes in heart failure by echocardiography, radionuclide ventriculography and cardiovascular magnetic resonance; are they interchangeable? Eur Heart J. 2000 Aug; 21(16): 1387-96.

[53] Wackers FJ, Berger HJ, Johnstone DE, et al. Multiple gated cardiac blood pool imaging for left ventricular ejection fraction: validation of the technique and assessment of variability. Am J Cardiol. 1979 Jun; 43(6): 1159-66.

[54] Schwartz RG, McKenzie WB, Alexander J, et al. Congestive heart failure and left ventricular dysfunction complicating doxorubicin 
therapy. Seven-year experience using serial radionuclide angiocardiography. Am J Med. 1987 Jun; 82(6): 1109-18.

[55] Miller TR, Wallis JW, Landy BR, Gropler RJ, Sabharwal CL. Measurement of global and regional left ventricular function by cardiac PET. J Nucl Med. 1994 Jun; 35(6): 999-1005.

[56] Bonow RO, Dilsizian V, Cuocolo A, Bacharach SL. Identification of viable myocardium in patients with chronic coronary artery disease and left ventricular dysfunction. Comparison of thallium scintigraphy with reinjection and PET imaging with $18 \mathrm{~F}$ fluorodeoxyglucose. Circulation. 1991 Jan; 83(1): 26-37.

[57] Szabo TL. Diagnostic Ultrasound Imaging: Inside Out. Academic Press; 2004. 549 p

[58] Popp RL, Wolfe SB, Hirata T, Feigenbaum H. Estimation of righ and left ventricular size by ultrasound. A study of the echoes from the interventricular septum. Am J Cardiol. 1969 Oct; 24(4): $523-$ 30.

[59] Feigenbaum H, Popp RL, Wolfe SB, et al. Ultrasound measurements of the left ventricle. A correlative study with angiocardiography. Arch Intern Med. 1972 Mar; 129(3): 461-7.

[60] Wyatt HL, Heng MK, Meerbaum S, et al. Cross-sectional echocardiography. II. Analysis of mathematic models for quantifying volume of the formalin-fixed left ventricle. Circulation. 1980 Jun; 61(6): 1119-25.

[61] Wyatt HL, Meerbaum S, Heng MK, Gueret P, Corday E. Crosssectional echocardiography. III. Analysis of mathematic models for quantifying volume of symmetric and asymmetric left ventricles. Am Heart J. 1980 Dec; 100(6 Pt 1): 821-8.

[62] Gérard O, Billon AC, Rouet JM, et al. Efficient model-based quantification of left ventricular function in 3-D echocardiography. IEEE Trans Med Imaging. 2002; 21(9): 105968.

[63] Montagnat J, Sermesant M, Delingette H, Malandain G, Ayache N. Anisotropic filtering for model-based segmentation of 4D cylindrical echocardiographic images. Pattern Recognit Lett. 2003; 24(4-5): 815-25.

[64] Zagrodsky V, Walimbe V, Castro-Pareja CR, et al. Registrationassisted segmentation of real-time 3-D echocardiographic data using deformable models. IEEE Trans Med Imaging. 2005; 24(9): 1089-99.

[65] Nillesen MM, Lopata RGP, Gerrits IH, et al. Segmentation of the Heart Muscle in 3-D Pediatric Echocardiographic Images. Ultrasound Med Biol. 2007; 33(9): 1453-62.

[66] Angelini ED, Laine a F, Takuma S, Holmes JW, Homma S. LV volume quantification via spatiotemporal analysis of real-time 3-D echocardiography. IEEE Trans Med Imaging. 2001; 20(6): 45769.

[67] Barbosa D, Dietenbeck T, Schaerer J, et al. B-spline explicit active surfaces: an efficient framework for real-time 3-D regionbased segmentation. IEEE Trans Image Process. United States; 2012 Jan; 21(1): 241-51.

[68] Papademetris X, Sinusas AJ, Dione DP, Duncan JS. Estimation of 3D left ventricular deformation from echocardiography. Med Image Anal. 2001; 5(1): 17-28.

[69] Boukerroui D, Basset O, Baskurt a, Gimenez G. A multiparametric and multiresolution segmentation algorithm of 3D ultrasonic data. IEEE Trans Ultrason Ferroelectr Freq Control. 2001; 48(1): 64-77.

[70] Zhu Y, Papademetris X, Sinusas A, Duncan JS. Segmentation of myocardial volumes from real-time 3D echocardiography using an incompressibility constraint. Med Image Comput Comput Assist Interv. 2007; 10(Pt 1): 44-51.

[71] Ye X, Noble JA, Atkinson D. 3-D freehand echocardiography for automatic left ventricle reconstruction and analysis based on multiple acoustic windows. IEEE Trans Med Imaging. 2002; 21(9): 1051-8.

[72] Angelini ED, Homma S, Pearson G, Holmes JW, Laine AF Segmentation of real-time three-dimensional ultrasound for quantification of ventricular function: a clinical study on right and left ventricles. Ultrasound Med Biol. 2005; 31(9): 1143-58.

[73] Corsi C, Saracino G, Sarti a, Lamberti C. Left ventricular volume estimation for real-time three-dimensional echocardiography. IEEE Trans Med Imaging. 2002; 21(9): 1202-8.

[74] Lin N, Yu W, Duncan JS. Combinative multi-scale level set framework for echocardiographic image segmentation. Med Image Anal. 2003; 7(4): 529-37.

[75] Sarti A, Corsi C, Mazzini E, Lamberti C. Maximum likelihood segmentation of ultrasound images with Rayleigh distribution. IEEE Trans Ultrason Ferroelectr Freq Control. 2005; 52(6): 94760

[76] Caiani EG, Corsi C, Zamorano J, et al. Improved semiautomated quantification of left ventricular volumes and ejection fraction using 3-dimensional echocardiography with a full matrix-array transducer: Comparison with magnetic resonance imaging. J Am Soc Echocardiogr. 2005; 18(8): 779-88.

[77] Ma M, Van Stralen M, Reiber JHC, Bosch JG, Lelieveldt BPF. Left ventricle segmentation from contrast enhanced fast rotating ultrasound images using three dimensional active shape models. Lect Notes Comput Sci (including Subser Lect Notes Artif Intell Lect Notes Bioinformatics). 2009; 5528: 295-302.

[78] Ma M, van Stralen M, Reiber JHC, Bosch JG, Lelieveldt BPF Model driven quantification of left ventricular function from sparse single-beat 3D echocardiography. Med Image Anal. Elsevier B.V.; 2010; 14(4): 582-93.

[79] Hansegård J, Orderud F, Rabben SI. Real-Time Active Shape Models for Segmentation of 3D Cardiac Ultrasound. Comput Anal Images Patterns. 2007; 4673: 157-64.

[80] Hansegård J, Urheim S, Lunde K, Rabben SI. Constrained active appearance models for segmentation of triplane echocardiograms. IEEE Trans Med Imaging. 2007; 26(10): 1391-400.

[81] Stralen M Van, Leung KYE, Voormolen MM, Jong N De, Steen FW Van Der. Automatic Segmentation of the Left Ventricle in 3D Echocardiography Using Active Appearance Models. Ultrasound. 2007; : 1480-3.

[82] Leung KYE, van Stralen M, Voormolen MM, et al. Improving 3D active appearance model segmentation of the left ventricle with Jacobian tuning [Internet]. Proc. SPIE. 2008. p. 69143B - 69143B -11 .

[83] Coppini G, Poli R, Valli G. Recovery of the 3-D shape of the left ventricle from echocardiographic images. IEEE Trans Med Imaging. 1995; 14(2): 301-17.

[84] Song M, Haralick RM, Sheehan FH, Johnson RK. Integrated surface model optimization for freehand three-dimensional echocardiography. IEEE Trans Med Imaging. 2002; 21(9): 1077_ 90

[85] Georgescu B, Zhou XS, Comaniciu D, Gupta a. Database-guided segmentation of anatomical structures with complex appearance. Proc IEEE Comput Soc Conf Comput Vis Pattern Recognit. 2005; 2: 429-36.

[86] Lu X, Georgescu B, Zheng Y, Otsuki J, Comaniciu D. AUTOMPR: Automatic Detection of Standard Planes in 3D Echocardiography. Biomedical Imaging: From Nano to Macro, 2008 ISBI 2008 5th IEEE International Symposium on. 2008. p. $1279-82$.

[87] Myronenko A, Song X, Sahn DJ. LV motion tracking from 3D echocardiography using textural and structural information. Med Image Comput Comput Assist Interv. 2007; 10(Pt 2): 428-35. 
[88] Elen A, Choi HF, Loeckx D, et al. Three-dimensional cardiac strain estimation using spatio-temporal elastic registration of ultrasound images: A feasibility study. IEEE Trans Med Imaging. 2008; 27(11): 1580-91.

[89] Heyde B, Barbosa D, Claus P, Maes F, D'hooge J. ThreeDimensional Cardiac Motion Estimation Based on Non-rigid Image Registration Using a Novel Transformation Model Adapted to the Heart. In: Camara O, Mansi T, Pop M, Rhode K, Sermesant $\mathrm{M}$, Young A, editors. Statistical Atlases and Computational Models of the Heart Imaging and Modelling Challenges SE - 17. Springer Berlin Heidelberg; 2013. p. 142-50.

[90] Piella G, Porras A, De Craene M, Duchateau N, Frangi A. Temporal Diffeomorphic Free Form Deformation to Quantify Changes Induced by Left and Right Bundle Branch Block and Pacing. In: Camara O, Mansi T, Pop M, Rhode K, Sermesant M, Young A, editors. Statistical Atlases and Computational Models of the Heart Imaging and Modelling Challenges SE - 16. Springer Berlin Heidelberg; 2013. p. 134-41.

[91] De Isla LP, Balcones DV, Fernández-Golfín C, et al. ThreeDimensional-Wall Motion Tracking: A New and Faster Tool for Myocardial Strain Assessment: Comparison With TwoDimensional-Wall Motion Tracking. J Am Soc Echocardiogr. 2009; 22(4): 325-30.

[92] Reant P, Barbot L, Touche C, et al. Evaluation of global left ventricular systolic function using three-dimensional echocardiography speckle-tracking strain parameters. J Am Soc Echocardiogr. Elsevier Inc; 2012; 25(1): 68-79.

[93] Saito K, Okura H, Watanabe N, et al. Comprehensive Evaluation of Left Ventricular Strain Using Speckle Tracking Echocardiography in Normal Adults: Comparison of ThreeDimensional and Two-Dimensional Approaches. J Am Soc Echocardiogr. Elsevier Inc; 2009; 22(9): 1025-30.

[94] Crosby J, Amundsen BH, Hergum T, et al. 3-D speckle tracking for assessment of regional left ventricular function. Ultrasound Med Biol. 2009; 35(3): 458-71.

[95] Seo Y, Ishizu T, Enomoto Y, Sugimori H, Aonuma K Endocardial surface area tracking for assessment of regional LV wall deformation with $3 \mathrm{D}$ speckle tracking imaging. JACC Cardiovasc Imaging. Elsevier Inc.; 2011; 4(4): 358-65.

[96] Tautz L, Hennemuth A, Peitgen H-O. Quadrature Filter Based Motion Analysis for 3D Ultrasound Sequences. In: Camara O, Mansi T, Pop M, Rhode K, Sermesant M, Young A, editors. Statistical Atlases and Computational Models of the Heart Imaging and Modelling Challenges SE - 20. Springer Berlin Heidelberg; 2013. p. 169-77.

[97] Alessandrini M, Liebgott H, Barbosa D, Bernard O. Monogenic Phase Based Optical Flow Computation for Myocardial Motion Analysis in 3D Echocardiography. In: Camara O, Mansi T, Pop M, Rhode K, Sermesant M, Young A, editors. Statistical Atlases and Computational Models of the Heart Imaging and Modelling Challenges SE - 19. Springer Berlin Heidelberg; 2013. p. 159-68.

[98] Somphone O, Dufour C, Mory B, et al. Motion estimation in 3D echocardiography using smooth field registration. Lect Notes Comput Sci (including Subser Lect Notes Artif Intell Lect Notes Bioinformatics). 2013; 7746 LNCS: 151-8.

[99] Duan Q, Angelini ED, Herz SL, et al. Region-Based Endocardium Tracking on Real-Time Three-Dimensional Ultrasound. Ultrasound Med Biol. 2009; 35(2): 256-65.

[100] Muraru D, Cucchini U, Mihăilă S, et al. Left ventricular myocardial strain by three-dimensional speckle-tracking echocardiography in healthy subjects: Reference values and analysis of their physiologic and technical determinants. J Am Soc Echocardiogr. 2014; 27(8): 858-72.

[101] Jacobs LD, Salgo IS, Goonewardena S, et al. Rapid online quantification of left ventricular volume from real-time threedimensional echocardiographic data. Eur Heart J. 2006; 27(4): 460-8.
[102] Kleijn S a., Aly MF a, Terwee CB, Van Rossum AC, Kamp O. Comparison between direct volumetric and speckle tracking methodologies for left ventricular and left atrial chamber quantification by three-dimensional echocardiography. Am J Cardiol. Elsevier Inc.; 2011; 108(7): 1038-44.

[103] Philips Healthcare Anatomical Intelligence [Internet]. [cited 2015 Jul 7]. Available from: http://www.usa.philips.com/healthcare-resources/featuredetail/anatomical-intelligence.html.

[104] Maffessanti F, Nesser H-J, Weinert L, et al. Quantitative evaluation of regional left ventricular function using threedimensional speckle tracking echocardiography in patients with and without heart disease. Am J Cardiol. Elsevier Inc.; 2009; 104(12): 1755-62.

[105] Kawamura R, Seo Y, Ishizu T, et al. Feasibility of left ventricular volume measurements by three-dimensional speckle tracking echocardiography depends on image quality and degree of left ventricular enlargement: Validation study with cardiac magnetic resonance imaging. J Cardiol. Japanese College of Cardiology; 2013; m(3): 1-9.

[106] Takeguchi T, Nishiura M, Abe Y, Ohuchi H, Kawagishi T Practical considerations for a method of rapid cardiac function analysis based on three-dimensional speckle tracking in a threedimensional diagnostic ultrasound system. J Med Ultrason. 2010; 37(2): 41-9.

[107] Georgescu B. Automated Volumetric Cardiac Ultrasound Analysis. 2008 .

[108] Zheng Y, Barbu A, Georgescu B, Scheuering M, Comaniciu D. Fast automatic heart chamber segmentation from 3D CT data using marginal space learning and steerable features. Proc IEEE Int Conf Comput Vis. 2007; : 1-8.

[109] Yang L, Georgescu B, Zheng Y, Meer P, Comaniciu D. 3D ultrasound tracking of the left ventricle using one-step forward prediction and data fusion of collaborative trackers. 26th IEEE Conf Comput Vis Pattern Recognition, CVPR. 2008;

[110] Mor-Avi V, Jenkins C, Kühl HP, et al. Real-Time 3-Dimensional Echocardiographic Quantification of Left Ventricular Volumes. Multicenter Study for Validation With Magnetic Resonance Imaging and Investigation of Sources of Error. JACC Cardiovasc Imaging. 2008; 1(4): 413-23.

[111] Siu SC, Rivera JM, Guerrero JL, et al. Three-dimensional echocardiography. In vivo validation for left ventricular volume and function. Circulation. 1993 Oct 1 [cited 2015 Jul 7]; 88(4): 1715-23.

[112] Hubka M, Bolson EL, McDonald J a., et al. Three-dimensional echocardiographic measurement of left and right ventricular mass and volume: In vitro validation. Int J Cardiovasc Imaging. 2002; 18(2): $111-8$

[113] Schmidt M, Ohazama C, Agyeman K, et al. Real-time threedimensional echocardiography for measurement of left ventricular volumes. Am J Cardiol. 1999; 84(12): 1434-9.

[114] Lee D, Fuisz a R, Fan PH, et al. Real-time 3-dimensional echocardiographic evaluation of left ventricular volume: correlation with magnetic resonance imaging--a validation study. J Am Soc Echocardiogr. 2001; 14(10): 1001-9.

[115] Kühl HP, Franke a., Merx M, et al. Rapid Quantification of Left Ventricular Function and Mass Using Transoesophageal Threedimensional Echocardiography: Validation of a Method that uses Long-axis Cutplanes*. Eur J Echocardiogr. 2000; 1(3): 213-21.

[116] Mannaerts HFJ, Van der Heide J a., Kamp O, et al. Quantification of left ventricular volumes and ejection fraction using freehand transthoracic three-dimensional echocardiography: Comparison with magnetic resonance imaging. J Am Soc Echocardiogr. 2003; 16(2): 101-9. 
[117] Kühl HP, Schreckenberg M, Rulands D, et al. High-resolution transthoracic real-time three-dimensional echocardiography: Quantitation of cardiac volumes and function using semiautomatic border detection and comparison with cardiac magnetic resonance imaging. J Am Coll Cardiol. 2004; 43(11): 2083-90.

[118] Jenkins C, Bricknell K, Hanekom L, Marwick TH Reproducibility and accuracy of echocardiographic measurements of left ventricular parameters using real-time three-dimensional echocardiography. J Am Coll Cardiol. 2004; 44(4): 878-86.

[119] Sugeng L, Mor-Avi V, Weinert L, et al. Quantitative assessment of left ventricular size and function: Side-by-side comparison of real-time three-dimensional echocardiography and computed tomography with magnetic resonance reference. Circulation. 2006; 114(7): 654-61.

[120] Van den Bosch AE, Robbers-Visser D, Krenning BJ, et al. Realtime transthoracic three-dimensional echocardiographic assessment of left ventricular volume and ejection fraction in congenital heart disease. J Am Soc Echocardiogr. 2006; 19(1): 16.

[121] Jenkins C, Chan J, Hanekom L, Marwick TH. Accuracy and Feasibility of Online 3-Dimensional Echocardiography for Measurement of Left Ventricular Parameters. J Am Soc Echocardiogr. 2006; 19(9): 1119-28.

[122] Soliman OII, Krenning BJ, Geleijnse ML, et al. A comparison between $\mathrm{QLAB}$ and tomtec full volume reconstruction for real time three-dimensional echocardiographic quantification of left ventricular volumes. Echocardiography. 2007; 24(9): 967-74.

[123] Soliman OII, Krenning BJ, Geleijnse ML, et al. Quantification of Left Ventricular Volumes and Function in Patients with Cardiomyopathies by Real-time Three-dimensional Echocardiography: A Head-to-Head Comparison Between Two Different Semiautomated Endocardial Border Detection Algorithms. J Am Soc Echocardiogr. 2007; 20(9): 1042-9.

[124] Hansegård J, Urheim S, Lunde K, Malm S, Rabben SI. Semiautomated quantification of left ventricular volumes and ejection fraction by real-time three-dimensional echocardiography. Cardiovasc Ultrasound. 2009; 7: 18.

[125] Muraru D, Badano LP, Piccoli G, et al. Validation of a novel automated border-detection algorithm for rapid and accurate quantitation of left ventricular volumes based on threedimensional echocardiography. Eur J Echocardiogr. 2010; 11(4): 359-68.

[126] Kleijn S a., Brouwer WP, Aly MF a, et al. Comparison between three-dimensional speckle-tracking echocardiography and cardiac magnetic resonance imaging for quantification of left ventricular volumes and function. Eur Heart J Cardiovasc Imaging. 2012; 13(10): 834-9.

[127] Miller C a., Pearce K, Jordan P, et al. Comparison of real-time three-dimensional echocardiography with cardiovascular magnetic resonance for left ventricular volumetric assessment in unselected patients. Eur Heart J Cardiovasc Imaging. 2012; 13(2): 187-95.

[128] Thavendiranathan P, Liu S, Verhaert D, et al. Feasibility, accuracy, and reproducibility of real-time full-volume 3D transthoracic echocardiography to measure LV volumes and systolic function: A fully automated endocardial contouring algorithm in sinus rhythm and atrial fibrillation. JACC Cardiovasc Imaging. Elsevier Inc.; 2012; 5(3): 239-51.

[129] Zhang Q Bin, Sun JP, Gao RF, et al. Novel single-beat fullvolume capture real-time three-dimensional echocardiography and auto-contouring algorithm for quantification of left ventricular volume: validation with cardiac magnetic resonance imaging. International journal of cardiology. Netherlands; 2013. p. 2946-8.

[130] Chang S a., Lee SC, Kim EY, et al. Feasibility of single-beat fullvolume capture real-time three-dimensional echocardiography and auto-contouring algorithm for quantification of left ventricular volume: Validation with cardiac magnetic resonance imaging. J Am Soc Echocardiogr. Elsevier Inc; 2011; 24(8): 853-9.
[131] Shibayama K, Watanabe $\mathrm{H}$, Iguchi N, et al Evaluation of automated measurement of left ventricular volume by novel realtime 3-dimensional echocardiographic system: Validation with cardiac magnetic resonance imaging and 2-dimensional echocardiography. J Cardiol. Japanese College of Cardiology; 2013; 61(4): 281-8.

[132] Tsang W, Salgo IS, Zarochev L, et al. Fully Automated Quantification of Left Ventricular and Left Atrial Volumes From Transthoracic 3D Echocardiography: a Validation Study. J Am Coll Cardiol. American College of Cardiology Foundation; 2013; 61(10): E904.

[133] Shimada YJ, Shiota T. A meta-analysis and investigation for the source of bias of left ventricular volumes and function by threedimensional echocardiography in comparison with magnetic resonance imaging. Am J Cardiol. Elsevier Inc.; 2011; 107(1): $126-38$.

[134] Dorosz JL, Lezotte DC, Weitzenkamp DA, Allen LA, Salcedo EE. Performance of 3-dimensional echocardiography in measuring left ventricular volumes and ejection fraction: a systematic review and meta-analysis. J Am Coll Cardiol. United States; 2012 May; 59(20): 1799-808.

[135] Marwick TH. Application of 3D echocardiography to everyday practice: Development of normal ranges is step 1. JACC Cardiovasc Imaging. Elsevier Inc.; 2012; 5(12): 1198-200.

[136] Aune E, Baekkevar M, Rodevand O, Otterstad JE. Reference values for left ventricular volumes with real-time 3-dimensional echocardiography. Scand Cardiovasc J. England; 2010 Feb; 44(1): $24-30$.

[137] Kaku K, Takeuchi M, Otani K, et al. Age- and gender-dependency of left ventricular geometry assessed with real-time threedimensional transthoracic echocardiography. J Am Soc Echocardiogr. United States; 2011 May; 24(5): 541-7.

[138] Fukuda S, Watanabe H, Daimon M, et al. Normal values of realtime 3-dimensional echocardiographic parameters in a healthy Japanese population: the JAMP-3D Study. Circ J. Japan; 2012; 76(5): 1177-81.

[139] Chahal NS, Lim TK, Jain P, et al. Population-based reference values for $3 \mathrm{D}$ echocardiographic $\mathrm{LV}$ volumes and ejection fraction. JACC Cardiovasc Imaging. United States; 2012 Dec; 5(12): 1191-7.

[140] Muraru D, Badano LP, Peluso D, et al. Comprehensive analysis of left ventricular geometry and function by three-dimensional echocardiography in healthy adults. J Am Soc Echocardiogr. Elsevier Inc; 2013; 26(6): 618-28.

[141] Poppe KK, Doughty RN, Whalley GA. Redefining norma reference ranges for echocardiography: a major new individual person data meta-analysis. Eur Heart $\mathbf{J}$ Cardiovasc Imaging. England; 2013 Apr; 14(4): 347-8.

[142] Poppe K. A meta-Analysis of echocardiographic measurements of the left heart for the development of normative reference ranges in a large international cohort: The EchoNoRMAL study. Eur Heart J Cardiovasc Imaging. 2014; 15(3): 341-8.

[143] Mor-Avi V, Yodwut C, Jenkins C, et al. Real-time 3D echocardiographic quantification of left atrial volume: Multicenter study for validation with CMR. JACC Cardiovasc Imaging. Elsevier Inc.; 2012; 5(8): 769-77.

[144] Buechel RR, Sommer G, Leibundgut G, et al. Assessment of left atrial functional parameters using a novel dedicated analysis too for real-time three-dimensional echocardiography: Validation in comparison to magnetic resonance imaging. Int $\mathrm{J}$ Cardiovasc Imaging. 2013; 29(3): 601-8.

[145] Miyasaka Y, Tsujimoto S, Maeba H, et al. Left atrial volume by real-time three-dimensional echocardiography: Validation by 64 slice multidetector computed tomography. J Am Soc Echocardiogr. Elsevier Inc; 2011; 24(6): 680-6. 
[146] Buechel RR, Stephan FP, Sommer G, et al. Head-to-head comparison of two-dimensional and three-dimensional echocardiographic methods for left atrial chamber quantification with magnetic resonance imaging. J Am Soc Echocardiogr. Elsevier Inc; 2013; 26(4): 428-35.

[147] Heo R, Hong G-R, Kim Y-J, et al. Semi-automated Quantification of Left Atrial Size Using 3 Beat Averaging Real Time 3D Echocardiography in Patients with Atrial Fibrillation; A Validation Study. Circulation. 2014 Nov 25; 130(Suppl 2): A19974-A19974.

[148] Lang RM, Badano LP, Mor-Avi V, et al. Recommendations for Cardiac Chamber Quantification by Echocardiography in Adults: An Update from the American Society of Echocardiography and the European Association of Cardiovascular Imaging. J Am Soc Echocardiogr. Elsevier Inc; 2015; 28(1): 1-39.e14.

[149] Rohner A, Brinkert M, Kawel N, et al. Functional assessment of the left atrium by real-time three-dimensional echocardiography using a novel dedicated analysis tool: Initial validation studies in comparison with computed tomography. Eur $\mathrm{J}$ Echocardiogr. 2011; 12(7): 497-505.

[150] Almeida N, Barbosa D, Heyde B, et al. Semi-automatic left-atrial segmentation from volumetric ultrasound using B-spline explicit active surfaces. Ultrasonics Symposium (IUS), 2014 IEEE International. 2014. p. 612-5.

[151] Van der Zwaan HB, Helbing W a, McGhie JS, et al. Clinical value of real-time three-dimensional echocardiography for right ventricular quantification in congenital heart disease: validation with cardiac magnetic resonance imaging. J Am Soc Echocardiogr. Elsevier Inc; 2010; 23(2): 134-40.

[152] Dragulescu A, Grosse-Wortmann L, Fackoury C, et al. Echocardiographic assessment of right ventricular volumes after surgical repair of tetralogy of Fallot: clinical validation of a new echocardiographic method. J Am Soc Echocardiogr. Elsevier Inc; 2011; 24(11): 1191-8.

[153] Selton-Suty C, Juillière Y. Non-invasive investigations of the right heart: how and why? Arch Cardiovasc Dis. 2009 Mar [cited 2015 Jun 15]; 102(3): 219-32.

[154] Ostenfeld E, Carlsson M, Shahgaldi K, Roijer A, Holm J. Manual correction of semi-automatic three-dimensional echocardiography is needed for right ventricular assessment in adults; validation with cardiac magnetic resonance. Cardiovasc Ultrasound. BioMed Central Ltd; 2012; 10(1): 1 .

[155] Dawood F a., Rahmat RW, Kadiman SB, Abdullah LN, Zamrin MD. A Hybrid Method for Endocardial Contour Extraction of Right Ventricle in 4-Slices from 3D Echocardiography Dataset. Adv Bioinformatics. Hindawi Publishing Corporation; 2014; 2014: 1-15.

[156] Kaul S, Tei C, Hopkins JM, Shah PM. Assessment of right ventricular function using two-dimensional echocardiography*1. Am Heart J. 1984; 107(3): 526-31.

[157] Helbing W a, Bosch HG, Maliepaard C, et al. Comparison of echocardiographic methods with magnetic resonance imaging for assessment of right ventricular function in children. Am J Cardiol. 1995; 76(8): 589-94.

[158] Gopal AS, Chukwu EO, Iwuchukwu CJ, et al. Normal values of right ventricular size and function by real-time 3-dimensional echocardiography: comparison with cardiac magnetic resonance imaging. J Am Soc Echocardiogr. 2007; 20(5): 445-55.

[159] Jenkins C, Chan J, Bricknell K, Strudwick M, Marwick TH. Reproducibility of right ventricular volumes and ejection fraction using real-time three-dimensional echocardiography: comparison with cardiac MRI. Chest. 2007; 131(6): 1844-51.

[160] Van Der Zwaan HB, Geleijnse ML, McGhie JS, et al. Right ventricular quantification in clinical practice: Two-dimensional vs. three-dimensional echocardiography compared with cardiac magnetic resonance imaging. Eur J Echocardiogr. 2011; 12(9): 656-64.

[161] Kjaergaard J, Petersen CL, Kjaer A, et al. Evaluation of right ventricular volume and function by $2 \mathrm{D}$ and $3 \mathrm{D}$ echocardiography compared to MRI. Eur J Echocardiogr. 2006; 7(6): 430-8.

[162] Linker DT, Moritz WE, Pearlman a S. A new three-dimensional echocardiographic method of right ventricular volume measurement: in vitro validation. J Am Coll Cardiol. American College of Cardiology Foundation; 1986; 8(1): 101-6.

[163] Sheehan FH, Kilner PJ, Sahn DJ, et al. Accuracy of KnowledgeBased Reconstruction for Measurement of Right Ventricular Volume and Function in Patients With Tetralogy of Fallot. Am J Cardiol. Elsevier Inc.; 2010; 105(7): 993-9.

[164] Pini R, Giannazzo G, Di Bari M, et al. Transthoracic threedimensional echocardiographic reconstruction of left and right ventricles: In vitro validation and comparison with magnetic resonance imaging. Am Heart J. 1997; 133(2): 221-9.

[165] Heusch a. Volumetric analysis of the right and left ventricle in a porcine heart model: comparison of three-dimensional echocardiography, magnetic resonance imaging and angiocardiography. Eur J Ultrasound. 1999; 9(3): 245-55.

[166] Schindera ST, Mehwald PS, Sahn DJ, Kececioglu D. Accuracy of real-time three-dimensional echocardiography for quantifying right ventricular volume: static and pulsatile flow studies in an anatomic in vitro model. J Ultrasound Med. 2002; 21(10): 106975

[167] Chen G, Sun K, Huang G. In vitro validation of right ventricular volume and mass measurement by real-time three-dimensional echocardiography. Echocardiography. 2006; 23(5): 395-9.

[168] Hoch M, Vasilyev N V., Soriano B, Gauvreau K, Marx GR. Variables Influencing the Accuracy of Right Ventricular Volume Assessment by Real-time 3-Dimensional Echocardiography: An In Vitro Validation Study. J Am Soc Echocardiogr. 2007; 20(5): 456-61.

[169] Jiang L, Siu SC, Handschumacher MD, et al. Three-dimensional echocardiography. In vivo validation for right ventricular volume and function. Circ . 1994 May 1; 89 (5 ): 2342-50.

[170] De Simone R, Wolf I, Mottl-Link S, et al. Intraoperative assessment of right ventricular volume and function. Eur J Cardiothoracic Surg. 2005; 27(6): 988-93.

[171] Grison A, Maschietto N, Reffo E, et al. Three-dimensional Echocardiographic Evaluation of Right Ventricular Volume and Function in Pediatric Patients: Validation of the Technique. J Am Soc Echocardiogr. 2007; 20(8): 921-9.

[172] Vogel M, Gutberlet M, Dittrich S, Hosten N, Lange PE. Comparison of transthoracic three dimensional echocardiography with magnetic resonance imaging in the assessment of right ventricular volume and mass. Heart. 1997; 78(2): 127-30.

[173] Fujimoto S, Mizuno R, Nakagawa Y, Dohi K, Nakano H. Estimation of the right ventricular volume and ejection fraction by transthoracic three-dimensional echocardiography. A validation study using magnetic resonance imaging. IntJCard Imaging. 1998; 14(6): 385-90.

[174] Papavassiliou DP, Parks WJ, Hopkins KL, Fyfe D a. Threedimensional echocardiographic measurement of right ventricula volume in children with congenital heart disease validated by magnetic resonance imaging. J Am Soc Echocardiogr. 1998; 11(8): 770-7.

[175] Prakasa KR, Dalal D, Wang J, et al. Feasibility and variability of three dimensional echocardiography in arrhythmogenic right ventricular dysplasia/cardiomyopathy. Am J Cardiol. 2006; 97(5): 703-9.

[176] Nesser HJ, Tkalec W, Patel AR, et al. Quantitation of right ventricular volumes and ejection fraction by three-dimensional echocardiography in patients: comparison with magnetic 
resonance imaging and radionuclide ventriculography. Echocardiography. 2006; 23(8): 666-80.

[177] Lu X, Nadvoretskiy V, Bu L, et al. Accuracy and Reproducibility of Real-Time Three-Dimensional Echocardiography for Assessment of Right Ventricular Volumes and Ejection Fraction in Children. J Am Soc Echocardiogr. 2008; 21(1): 84-9.

[178] Niemann PS, Pinho L, Balbach T, et al. Anatomically Oriented Right Ventricular Volume Measurements With Dynamic ThreeDimensional Echocardiography Validated by 3-Tesla Magnetic Resonance Imaging. J Am Coll Cardiol. 2007; 50(17): 1668-76.

[179] Grewal J, Majdalany D, Syed I, Pellikka P, Warnes C a. ThreeDimensional Echocardiographic Assessment of Right Ventricular Volume and Function in Adult Patients With Congenital Heart Disease: Comparison With Magnetic Resonance Imaging. J Am Soc Echocardiogr. Elsevier Inc; 2010; 23(2): 127-33.

[180] Leibundgut G, Rohner A, Grize L, et al. Dynamic assessment of right ventricular volumes and function by real-time threedimensional echocardiography: a comparison study with magnetic resonance imaging in 100 adult patients. J Am Soc Echocardiogr. Elsevier Inc; 2010; 23(2): 116-26.

[181] Zhang Q Bin, Sun JP, Gao RF, et al. Feasibility of single-beat full-volume capture real-time three-dimensional echocardiography for quantification of right ventricular volume: Validation by cardiac magnetic resonance imaging. Int $\mathrm{J}$ Cardiol. Elsevier Ireland Ltd; 2013; 168(4): 3991-5.

[182] Tamborini G, Marsan NA, Gripari P, et al. Reference Values for Right Ventricular Volumes and Ejection Fraction With Real-Time Three-Dimensional Echocardiography: Evaluation in a Large Series of Normal Subjects. J Am Soc Echocardiogr. Elsevier Inc; 2010; 23(2): 109-15.

[183] Maffessanti F, Muraru D, Esposito R, et al. Age-, body size-, and sex-specific reference values for right ventricular volumes and ejection fraction by three-dimensional echocardiography: A multicenter echocardiographic study in 507 healthy volunteers. Circ Cardiovasc Imaging. 2013; 6(5): 700-10. 